\title{
Fibroblast activation protein $\alpha$-positive pancreatic stellate cells promote the migration and invasion of pancreatic cancer by CXCL1-mediated Akt phosphorylation
}

\author{
Zhang Wen ${ }^{1,2 \#}$, Qiaofei Liu ${ }^{2 \#}$, Jihua Wu ${ }^{1 \#}$, Banghao Xu' ${ }^{1}$,jilong Wang ${ }^{1}$, Lizhou Liang ${ }^{1}$, Ya Guo ${ }^{1}$, \\ Minhao Peng ${ }^{1}$, Yupei Zhao', Quan Liao ${ }^{2}$ \\ ${ }^{1}$ Department of Hepatobiliary Surgery and Liver Transplantation, The First Affiliated Hospital of Guangxi Medical University, Nanning 530021, \\ China; ${ }^{2}$ Department of General Surgery, Peking Union Medical College Hospital, Peking Union Medical College \& Chinese Academy of Medical \\ Sciences, Beijing 100730, China \\ Contributions: (I) Conception and design: Z Wen, Q Liu, J Wu, Y Zhao, Q Liao; (II) Administrative support: Y Zhao, Q Liao; (III) Provision of study \\ materials or patients: Y Zhao, Q Liao; (IV) Collection and assembly of data: Z Wen, Q Liu, J Wu, B Xu, L Liang, Y Guo, M Peng; (V) Data analysis \\ and interpretation: Z Wen, Q Liu, J Wu, B Xu, L Liang, Y Guo, M Peng; (VI) Manuscript writing: All authors; (VII) Final approval of manuscript: \\ All authors. \\ "These authors contributed equally to this work. \\ Correspondence to: Prof. Quan Liao; Prof. Yupei Zhao. Department of General Surgery, Peking Union Medical College Hospital, Peking Union \\ Medical College \& Chinese Academy of Medical Sciences, 1\# Shuai Fu Yuan, Dongcheng District, Beijing 100730, China. Email: lqpumc@126.com; \\ zhao8028@263.net.
}

Background: Pancreatic stellate cells (PSCs) is a highly heterogeneic stroma cell population in pancreatic cancer tissue. Interaction between PSCs and pancreatic cancer cells has not been well elucidated. This research was aimed to study the relationship between fibroblast activation protein $\alpha(\mathrm{FAP} \alpha)$-positive $(\mathrm{FAP} \alpha+)$ PSCs and the pathological features and prognosis of pancreatic cancer. The effects and mechanisms of FAP $\alpha$ + PSCs in pancreatic cancer were also explored.

Methods: Tissue microarray analysis was used to detect FAP $\alpha$ expression in tumor and adjacent tissues. The relationship between FAP $\alpha$ expression and pancreatic pathological features and prognosis were analyzed. The effects of FAP $\alpha+$ PSCs on the proliferation, migration and invasion of pancreatic cancer were detected in vitro and in vivo. A cytokine chip was used to detect the differential expression of cytokines in FAP $\alpha$ positive $(\mathrm{FAP} \alpha+)$ and FAP $\alpha$-negative (FAP $\alpha-)$ PSCs. Phosphorylated tyrosine kinase receptors were detected by a human phosphotyrosine kinase receptor protein chip. The interaction between differential cytokine and tyrosine kinase receptors was detected by immunoprecipitation.

Results: Compared with the adjacent tissues, pancreatic cancer stromal tissues showed high FAP $\alpha$ expression. FAP $\alpha$ was mainly expressed in the PSCs. FAP $\alpha+$ PSCs were associated with lymph node metastasis. Higher numbers of FAP $\alpha+$ PSCs predicted shorter survival. Pancreatic cancer cells released TGF $\beta 1$ and induced PSCs to express FAP $\alpha$. FAP $\alpha+$ PSCs released the chemokine CXCL1 and promoted the phosphorylation of the tyrosine kinase receptors EphB1 and EphB3 in pancreatic cancer cells. CXCL1, EphrinB1, and EphrinB3 worked together to promote the migration and invasion of pancreatic cancer cells by Akt phosphorylation. Talabostat (PT100), an FAP $\alpha$ inhibitor, inhibited the roles of FAP $\alpha+$ PSCs.

Conclusions: FAP $\alpha+$ PSCs can promote the migration, invasion, and metastasis of pancreatic cancer by the Akt signaling pathway. This interaction of FAP $\alpha+$ PSCs with pancreatic cancer cells may become a new strategy for the comprehensive treatment of pancreatic cancer.

Keywords: FAP $\alpha$; pancreatic stellate cells (PSCs); pancreatic cancer; migration; invasion

Submitted Jun 28, 2019. Accepted for publication Sep 11, 2019.

doi: 10.21037/atm.2019.09.164

View this article at: http://dx.doi.org/10.21037/atm.2019.09.164 


\section{Introduction}

The prognosis of pancreatic cancer is extremely poor, with a 5 -year survival rate of $<10 \%$ (1). The stromal components of pancreatic cancer promote tumor occurrence and development (2-5). In the normal pancreas, pancreatic stellate cells (PSCs) are located around the pancreatic acinus and in the interlobular space, thereby accounting for $4 \%$ of the total number of cells $(6,7)$. PSCs, as the important components of pancreatic cancer stroma, play an important role in pancreatic cancer development. Pancreatic cancer cells release mitotic and fibrotic-stimulating factors, causing PSCs to exhibit an activated phenotype. Activated PSCs secrete various chemical and growth factors affecting the biological behavior of pancreatic cancer cells in proliferation, apoptosis, invasion, metastasis, angiogenesis, and chemoresistance $(8,9)$.

FAP $\alpha$ is a membrane serine peptidase that is a member of the type II serine protease family, which can break the peptide bonds of amino acids. The proteolytic activity of FAP $\alpha$ enhances the ability of tumor cells to invade the extracellular matrix and promote tumor proliferation (10). FAP $\alpha$ is expressed in the extracellular matrix of epithelialderived malignant tumors, embryonic developmental tissue, and wound healing, but not in normal adult tissues (11-13). FAP $\alpha$ can dissociate growth factors bound to matrix proteins by protease hydrolysis and promotes tumor growth and angiogenesis or degrades the extracellular matrix of adjacent cells, further promoting tumor cell migration, invasion, and metastasis. Han et al. (14) found that tumor cells stably expressing FAP $\alpha$ grew considerably faster than the control group by establishing a mouse model of breast cancer. Clinical studies on colon cancer have found that patients with high FAP $\alpha$ expression in the colon cancer stroma are likely to relapse after surgery and have short survival rates (15). However, the roles and mechanisms of FAP $\alpha$-positive PSCs in regulating the malignant behaviors of pancreatic cancer remain largely unknown.

\section{Methods}

\section{Pathological specimens}

The pathological specimens were obtained from pancreatic cancer patients admitted to the Peking Union Medical College Hospital of Chinese Academy of Medical Sciences. All cases were surgically removed and confirmed by pathological examination. The exclusion criteria were as follows: neoadjuvant treatment, incomplete case data, no follow-up data and difficulty in preparing paraffin specimens for immunization slices required for histochemical staining. This study included 56 patients with pancreatic cancer, including 24 male cases and 32 female patients. Among these patients, 37 were aged $<65$ years, and 19 were aged $>65$ years. The tumor site was located in the pancreatic heads of 36 patients and in the pancreas body or pancreas tail of 20 cases. Thirty-two cases had low and moderate differentiation, and 24 had high differentiation. Fortyfour cases had Tumor Node Metastasis (TNM, $7^{\text {th }}$ edition) stages 1 or 2, and 12 had TNM stages 3 or 4 . Meanwhile, 46 patients underwent $\mathrm{R} 0$ resection, and 10 underwent $\mathrm{R} 1$ resection. All the patients signed the agreement for scientific research use of the samples. The study was reviewed by the Ethics Committee of Peking Union Medical College Hospital, Chinese Academy of Medical Sciences.

\section{Immunobistochemical staining and evaluation}

Paraffin sections were prepared by screening the pathological tissue sections of cancer tissues and adjacent tissues of pancreatic cancer. The paraffin sections used for immunohistochemistry were dewaxed, subjected to endogenous peroxidase removal, and incubated with primary (rabbit anti human FAP $\alpha$ polycolonal antibody, abcam, ab28244; mouse anti human SMA monocolonal antibody, Dako, Clone 1A4) and secondary antibodies (ZSGB-Bio, PV-6001 kit). Following DAB color development, the sections were dehydrated, mounted, and observed under a microscope. Positive expression was indicated by the appearance of brownish-yellow particles in the cytoplasm of the cells. The results of immunohistochemical staining were evaluated by two pathologists who were blinded to the clinicopathological data. Brownish-yellow particles appeared as a marker of positive expression in the cytoplasm of the cells. The FAP $\alpha$ expression evaluation criteria were as follows: dyeing area $\leq 10 \%$ was scored as 0 points; $11 \% \leq 25 \%$ as 1 point; $>26 \% \leq 50 \%$ as 2 points; $>51 \%$ as 3 points. A negative staining intensity was scored as 0 points, weak staining as 1 point, intermediate staining as 2 points, and strong staining as 3 points. The classification of slice staining was divided according to the sum of the stained area and staining intensity score: $\leq 3$ indicated low expression of FAP $\alpha$ (FAP $\alpha$ negative, FAP $\alpha-) ;>3$ indicated high expression of FAP $\alpha(\mathrm{FAP} \alpha$ positive, $\mathrm{FAP} \alpha+)(16)$.

\section{Cell culture}

The human pancreatic cancer cell lines AsPc1, MIAPaCa2, 
SW1990, SU86.86, and T3M4 were purchased from the Cell Line Bank of Chinese Academy of Medical Sciences. BxPC3, Capan1, and PANC1 were donated by Professor H. Freiss of the Technical University of Munich, Germany. Nontumor tissues that were surgically removed from pancreatic cancer patients were collected, and human primary PSCs were extracted by the outgrowth method. The isolation and culture of human primary PSCs were performed as described previously $(6,17)$. The original human PSCs were extracted before the 10th generation for subsequent experiments. BxPC3 was cultured in RPMI1640 medium (HyClone, SH30809.01B) containing 10\% FBS (HyClone, SH30084.03). AsPc1, MIAPaCa2, SW1990, SU86.86, T3M4, Capan1, PANC1, and human PSCs were cultured in DMEM/high-glucose medium containing $10 \%$ FBS (HyClone, SH30022.01B). The cells were cultured at $37^{\circ} \mathrm{C}$ and $5 \% \mathrm{CO}_{2}$.

\section{Induction and identification of FAPa+ PSCs in vitro}

Human primary PSCs were seeded on Nunc Lab-Tek II chamber coverslips and were cultivated in different media for $48 \mathrm{~h}$ to induce FAP $\alpha+$ PSCs: (I) serum-free DMEM/ F12 medium with or without TGF $\beta 1$ (R\&D system, 240$\mathrm{B}-010,10 \mathrm{ng} / \mathrm{mL}$ ); (II) human pancreatic cancer cell line (BxPC3, Capan1, or PANC1)-conditioned medium (CM) with or without TGFß1 (10 ng/mL). Formalin solution was added, and the samples were fixed for $30 \mathrm{~min}$. Next, immunofluorescence blocking buffer was added and blocked for $30 \mathrm{~min}$. Thereafter, a PBS solution containing antihuman FAP $\alpha$ rabbit polyclonal antibody (Abcam, ab28244) (1:100 ratio) was added. Next, the samples were incubated at room temperature for $3 \mathrm{~h}$ in the dark, followed by the addition of PBS solution containing anti-rabbit IgG-FITC antibody (1:200) (Sigma-Aldrich, F0382) and incubation at room temperature for $45 \mathrm{~min}$ in the dark. DAPI staining solution was then added to the samples, followed by staining for $30 \mathrm{~min}$ and observation under an inverted fluorescence microscope.

\section{Detection of TGFß1 and CXCL1 expression in pancreatic cancer cells by enzyme-linked immunosorbent assay (ELISA)}

Pancreatic cancer cell supernatants were collected, and then $50 \mu \mathrm{L}$ of the dilution solution was added to each well of a 96-well plate in an ELISA kit (TGFß1 and CXCL1; eBioscience, Austria). Next, $50 \mu \mathrm{L}$ of the standard product, control sample, or sample to be tested was added to the 96well plate. The film was attached and incubated at room temperature for $1.5 \mathrm{~h}$. The liquid from each well was pipetted, and $200 \mu \mathrm{L}$ of the substrate solution was added to each well. The well was incubated for $15 \mathrm{~min}$ at room temperature in the dark. Next, $50 \mu \mathrm{L}$ of the stop reaction solution was added to each well, mixed, and placed on a microplate reader for detection.

\section{Western blot analysis of protein expression}

The cell lysate was added, fully lysed, and centrifuged at $12,000 \mathrm{rpm}$ for $10 \mathrm{~min}$ at $4{ }^{\circ} \mathrm{C}$. The total protein of the supernatant was aspirated, and the total protein concentration was determined using the BCA method. The protein was submerged in boiling water for $5 \mathrm{~min}$ and centrifuged at $12,000 \mathrm{rpm}$ for $4 \mathrm{~min}$ at $4{ }^{\circ} \mathrm{C}$. The lower $(6 \%)$ and upper layers of the concentrated gel (8\%) were prepared. Next, the protein loading amount obtained was $40 \mu \mathrm{g} / \mathrm{well}$. After electrophoresis and transfer, the strip was blocked with $5 \%$ skim milk powder for $40 \mathrm{~min}$. Primary (rabbit anti human FAP $\alpha$ polycolonal antibody, abcam, ab28244; rabbit anti human CXCR2 polycolonal antibody, EphB1 monoclonoal antibody, EphB3 monoclonal antibody, abcam, ab14935, EPR6457, EPR8280; rabbit anti human Akt monoclonal antibody, Cell Signal Technology, 4691; rabbit anti human phosphorylated Akt monoclonal antibody, Cell Signal Technology, 4060) and $\beta$-actin antibodies (mouse anti human $\beta$-actin monoclonal antibody, Santa cruz,Sc-47778) were diluted in $5 \%$ BSA according to the specification. The band-of-interest protein was incubated and slowly shaken at $4{ }^{\circ} \mathrm{C}$ overnight. The secondary antibody was added and incubated for $1 \mathrm{~h}$. Next, ECL illuminant was added to the target strip, and the image was placed in a FluorChem SP instrument.

\section{Flow cytometry for FAPa expression detection}

The cells were trypsinized and centrifuged. PBS containing anti-human FAP $\alpha$ polyclonal antibody (Abcam, ab28244) was added at a ratio of 1:500. Isotype control IgG (MACS, 130-092-213) was used as the control group and then incubated for $2 \mathrm{~h}$. Meanwhile, PBS containing FITClabeled secondary antibody (Sigma-Aldrich, F0382) was added at 1:1,000 and incubated for $45 \mathrm{~min}$ in the dark. PBS was added and centrifuged at $1,000 \mathrm{~g}$ and $4{ }^{\circ} \mathrm{C}$. Thereafter, the cells were resuspended in PBS, and flow cytometry was performed. 


\section{CCK8 assay for the effects of FAPa+ and FAPa-PSCs on the proliferation of pancreatic cancer cells}

Human primary PSCs were seeded in the upper chamber of a cocultured 96-well plate, and the number of inoculated cells was 4,000/well. Next, DMEM/F12 medium with or without TGF $\beta 1(10 \mathrm{ng} / \mathrm{mL})$ was added. The cells were then cultured for $48 \mathrm{~h}$ to obtain FAP $\alpha+$ and FAP $\alpha$ - PSCs. BxPC3, Capan1, and PANC1 were seeded in the lower chamber of the cocultured 96-well plate at 1,000/well. At the same time, the upper chamber containing FAP $\alpha+$ and FAP $\alpha$ - PSCs was placed and cocultured with pancreatic cancer cells for 24, 48, and $72 \mathrm{~h}$. Thereafter, the upper chamber containing FAP $\alpha+$ and FAP $\alpha$ - PSCs was extracted. Next, $10 \mu \mathrm{L}$ of CCK8 reagent (DOJINDO, CCK8 KIT) was added to the lower chamber containing pancreatic cancer cells, placed in $5 \% \mathrm{CO}_{2}$ cell culture at $37^{\circ} \mathrm{C}$, and incubated for $3 \mathrm{~h}$. The 96 -well plate was extracted and placed in a microplate reader, and the absorbance value was read at a wavelength of $450 \mathrm{~nm}$.

\section{Transwell method for migration and invasion detection}

Human primary PSCs were seeded in the upper chamber of a cocultured 96-well plate, and the number of inoculated cells was 4,000/well. DMEM/F12 medium and DMEM/ F12 medium containing TGF $\beta 1(10 \mathrm{ng} / \mathrm{mL})$ were added. The cells were cultured for $48 \mathrm{~h}$ to obtain FAP $\alpha+$ and FAP $\alpha-$ PSCs and were grouped as follows: FAP $\alpha+$ PSCs, FAP $\alpha-$ PSCs, FAP $\alpha+$ PSCs+PT100 (FAP $\alpha$ inhibitor), and the control group (no PSC). In the invasion experiment, $50 \mu \mathrm{L}$ of Matrigel gel was added to the Transwell and was placed in a $37^{\circ} \mathrm{C}$ cell incubator for $4 \mathrm{~h}$ to allow the Matrigel to coagulate. BxPC3, Capan1, and PANC at $1,200 \mu \mathrm{L}$ each with 40,000 cells/well were added to the upper chamber of the Transwell. The lower chamber medium was aspirated, added to $500 \mu \mathrm{L}$ of fresh serum-free medium, and placed in a $5 \% \mathrm{CO}_{2}$ cell incubator at $37^{\circ} \mathrm{C}$ for $24 \mathrm{~h}$. Meanwhile, the upper chamber was extracted, and hematoxylin-eosin staining solution was added. Subsequently, five high-power microscope fields $(400 \times)$ were randomly selected under a microscope, and the cells were observed and counted.

\section{Effects of FAPa+ and FAPQ-PSCs on pancreatic cancer formation in nude mice}

Five- to 6-week-old athymic nude mice (BALB/c, nude) were purchased from Beijing Weitong Lihua Experimental
Animal Technology Co., Ltd. All the animal studies were performed in accordance with the principles and procedures set by the Laboratory Animal Management and Use Committee of the Chinese Academy of Medical Sciences. $\mathrm{FAP} \alpha+$, FAP $\alpha-$ PSCs, BxPC3, and PANC1 were injected subcutaneously into the back of nude mice using a $1-\mathrm{mL}$ syringe according to the following settings: $\mathrm{BxPC} 3$ cells alone $(4 \times 106), \mathrm{BxPC} 3$ cells $+\mathrm{FAP} \alpha-\mathrm{PSCs}\left(4 \times 10^{6}\right)$, BxPC3 cells+ FAP $\alpha+$ PSCs; PANC1 cells alone $\left(6 \times 10^{6}\right)$, PANC1 cells + FAP $\alpha$ - PSCs $\left(6 \times 10^{6}\right)$, and PANC1 cells+ FAP $\alpha+$ PSCs. Six groups were generated, each containing four nude mice. After the injection, the mice were observed daily. The long diameter (A) and broad diameter (B, mm) of the subcutaneous tumor were measured weekly using a Vernier caliper, and the volume of the tumor $\left(\mathrm{mm}^{3}\right)$ was calculated as follows: $\left(A \times B^{2}\right) / 2$. After 4 weeks, the mice were euthanized to obtain xenografts.

\section{Effects of FAPa + and FAP - PSCs on pancreatic cancer cell metastasis in nude mice}

The cells were mixed in the following ratios with $100 \mu \mathrm{L}$ of PBS: PANC1 cells alone $\left(1 \times 10^{6}\right)$, PANC1 cells+ FAP $\alpha-$ PSCs $\left(1 \times 10^{6}\right)$, and PANC1 cells+ FAP $\alpha+$ PSCs $\left(1 \times 10^{6}\right)$. The experiment was divided into four groups with five mice in each group, as follows: PANC1 alone, PANC1+ $\mathrm{FAP} \alpha-\mathrm{PSC}$, PANC1+FAP $\alpha+\mathrm{PSC}$, and PANC1+FAP $\alpha+$ PSCs+PT100. Using $1 \%$ chloral hydrate at $4-\mathrm{g} / \mathrm{kg}$ dose, the mice were anesthetized by intraperitoneal injection. The surgical area was disinfected with iodophor, the left inferior costal area was incised, and the abdominal cavity was cut in layers. The spleen was gently resected from the surgical incision. The lower pole of the spleen was also exposed and slowly injected with $100 \mu \mathrm{L}$ of the cell suspension. The needle was removed, and the site was pressed with a gelatin sponge into the needle. After properly stopping the bleeding, the layer was stitched with an absorbable suture. On the first day after surgery, each mouse in group 4 was administered PT100 intragastrically at a dose of $50 \mu \mathrm{g} / \mathrm{day}$ for 2 weeks (18). The general condition of the mice was observed daily. After 2 weeks, the mice were euthanized, and the number of liver metastatic nodules was calculated.

\section{Cytokine chip detection}

FAP $\alpha+$ and FAP $\alpha-$ PSCs were cultured in serum-free DMEM/F12 for $25 \mathrm{~h}$. The medium was aspirated, and the cell debris was filtered through a Millipore filter $(0.2 \mu \mathrm{m})$. 
Next, the filtered medium was obtained for chip detection (Shanghai Kangcheng Bioengineering Co. Ltd).

\section{Phosphotyrosine kinase receptor protein chip detection}

Pancreatic cancer cells were cocultured with FAP $\alpha+$ and FAP $\alpha$ - PSCs in a 6-well plate. These cells were added to cell lysis buffer for $30 \mathrm{~min}$ and centrifuged at $10{ }^{\circ} \mathrm{C}$ for 10 min at 12,000 rpm. Next, the supernatant protein solution was extracted. The BCA method was used to determine the protein concentration, and the chip was detected by Shanghai Kangcheng Bioengineering Co. Ltd.

\section{Co-immunoprecipitation (Co-IP) procedure}

The cells were digested and centrifuged, and the cell pellet was extracted and placed on ice. The cell lysate required for co-IP was added and shaken in an oscillating mixer for $30 \mathrm{~min}$ and then was centrifuged at $12,000 \mathrm{rpm}$ at $4{ }^{\circ} \mathrm{C}$ for $10 \mathrm{~min}$. The supernatant protein extract was also removed. Next, $10 \mu \mathrm{L}$ of anti-human EphB1 (Abcam, EPR6457), or EphB3 (Abcam, EPR8280), or chemokine receptor 2 (CXCR2) antibody (Abcam, Ab14935) was added to the cell lysate. Meanwhile, $10 \mu \mathrm{L}$ of normal rabbit IgG was added to the control group, placed on a silent mixer, and incubated at $4{ }^{\circ} \mathrm{C}$ for $1 \mathrm{~h}$. The ProteinA/G beads were removed and centrifuged to remove the glycerin from the supernatant. The beads were added, mixed with the cell lysate-antibody, placed on a silent mixer, and incubated overnight at $4{ }^{\circ} \mathrm{C}$. Next, $1 \mathrm{~mL}$ of lysate was added to each of the experimental and control groups. The ProteinA/G beads were washed three times and centrifuged at 4,000 rpm for $2 \mathrm{~min}$. The supernatant was removed, and $26 \mu \mathrm{L}$ of $2 \times$ SDS loading buffer was added and boiled for 5 min. Finally, Western blot analysis was performed.

\section{siRNA interference experiment}

The siRNA design and synthesis were performed according to the siRNA design principles and Eph1:NC_000003.11 (134514099..134979309) and Eph3:NC_000003.11 (184279587..184300 196) sequences in GenBank. These sequences were designed using the Invitrogen BLOCK-IT designer from Invitrogen (Shanghai, China). The chemically synthesized pairs of EphB1-siRNA sequences are as follows: A: EphB1siRNA, 5'-GCGAUAAGCUCCAGCAUUATT-3' and 5'-UAAUGCUGGAGCUUAUCGCTT-3'; B: EphB1-
siRNA, 5'-GUGCCCAUCAAACUCUACUTT-3' and 5'-AGUAGAGUUUGAUGGGCACTT-3'; C: EphB1siRNA, 5'-ACCUUCAACUUGUAUUACUTT-3' and 5'-AGUAAUACAAGUUGAAGGUTT-3'; D: negative control-RNA, 5'-UUCUCCGAACGUGUCACGUTT-3' and 5'-ACGUGACACGUUCGGAGATT-3'. The siRNA sequences of each pair of EphB3 were as follows: A: EphB3siRNA, 5'-GCCGUAAUAUCACCACAAATT-3' and 5'-UUGUGGUGAUAUUCACGGCTT-3'; B: EphB3siRNA, 5'-CCUGGAAUGAAGGUUUAUATT-3' and 5'-UAUAAACCUUCAUUCCAGGTT-3'; C: EphB3siRNA, 5'-GAGGUGUGA UCUCCAAUGUTT-3' and 5'-ACAUUGGAGAUCACACCUCTT-3'; D: negative control-RNA, 5'-UUCUCCGAACGUGUCACGUTT-3' and 5'-ACGUGACA CGUUCGGAGAATT-3'. BxPC3 and PANC1 were inoculated in a 6-well plate. When the cells were grown to $80 \%$, the corresponding serumfree medium was added to continue the culture for $12 \mathrm{~h}$ for siRNA transfection. The experiment was divided into the following groups: group A, the negative control RNA group; B-D groups, the siRNA groups. After $48 \mathrm{~h}$ of culture, the total protein of each group was extracted and detected by Western blotting.

\section{Statistical analysis}

Statistical analysis was performed using SPSS 13.0 (SPSS Inc., Chicago, IL, USA). The survival time was analyzed using the Kaplan-Meier method. The log-rank test was used to analyze the difference in the survival curves between different groups by single-factor analysis. Multivariate survival was analyzed using the Cox proportional hazard regression model. Measurement data were expressed as the means \pm standard deviation. The two groups were compared using $t$-test. One-way ANOVA was also applied between groups. Chi-squared test and Fisher's exact probability method were used to compare the data between the groups. $\mathrm{P}<0.05$ was considered statistically significant.

\section{Results}

FAP a expression in buman pancreatic cancer and adjacent tissues

$\mathrm{FAP} \alpha$ was almost absent in the paracancerous tissues [Figure $1 A(\mathrm{a}, \mathrm{b})]$. The positive expression of $\mathrm{FAP} \alpha$ protein was mainly located in the stroma tissues [Figure $1 A(\mathrm{c}, \mathrm{d})]$. $\mathrm{FAP} \alpha$ expression was remarkable in the immediate vicinity 
A
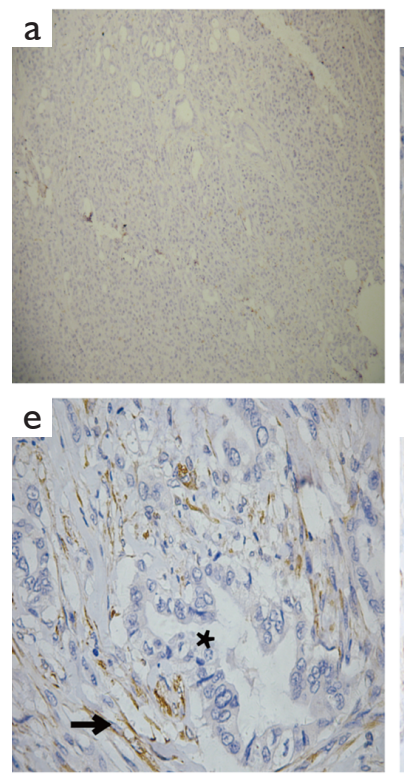

B

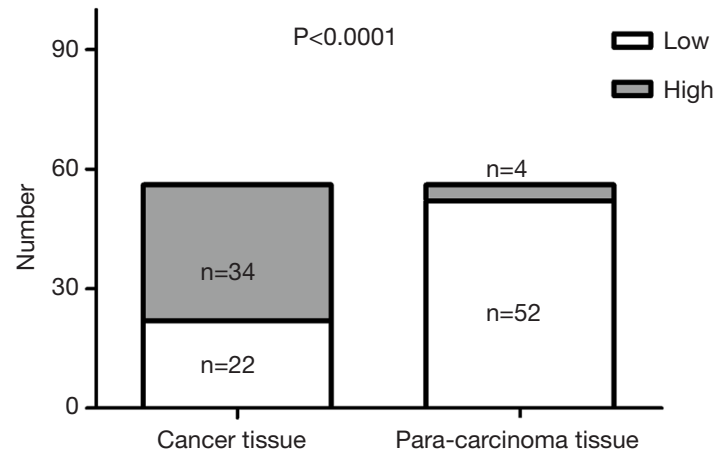

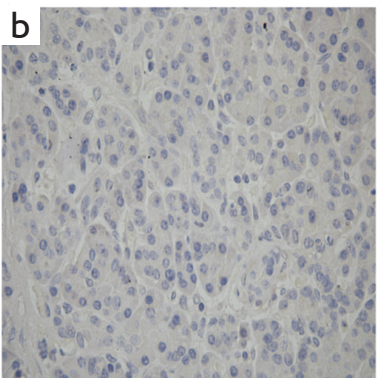
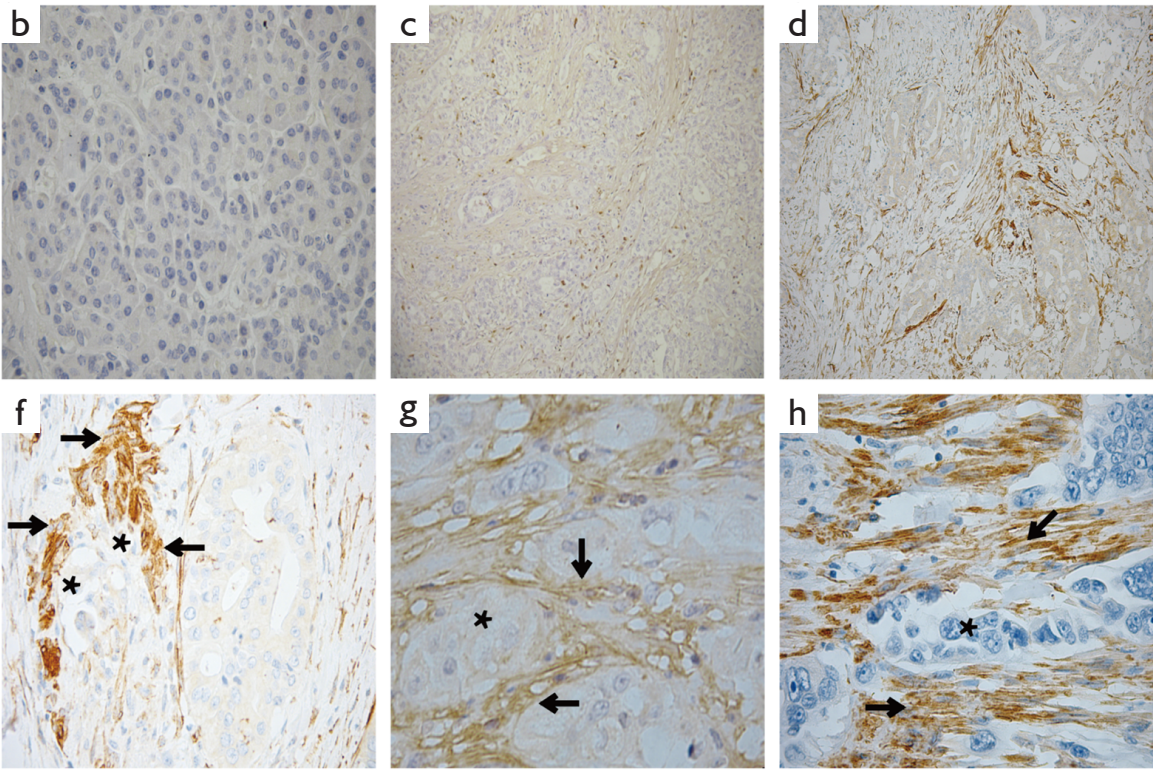

C

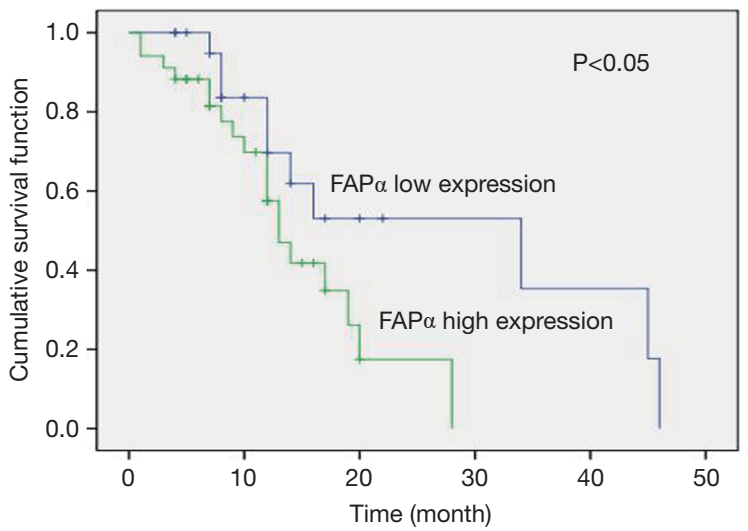

Figure 1 Expressions of FAPa in tumoral and adjacent tissues and its survival impact on pancreatic cancer patients. (A) FAP $\alpha$ is absent in adjacent pancreatic cancer cell tissues (a,b). FAP $\alpha$ expression in pancreatic cancer tissues (c). Low FAP $\alpha$ expression (d). High FAP $\alpha$ expression. FAP $\alpha$ expression is remarkable in the region $(\rightarrow)$ adjacent to pancreatic cancer cells $\left({ }^{*} ; \mathrm{e}, \mathrm{f}\right)$. The expression of the marker SMA of myofibroblast-like cells can be seen in the interstitial region of pancreatic cancer-expressing FAP $\alpha\left({ }^{*}\right.$ pancreatic cancer cells $\rightarrow$ pancreatic cancer stroma). (g) FAP $\alpha$ immunohistochemical staining. (h) SMA immunohistochemical staining (a, c, d, ×100; b, e, f, g, ×400); (B) comparison of the FAP $\alpha$ expression scores in pancreatic cancer and adjacent tissues; (C) effect of FAP $\alpha$ expression on the overall survival of patients with pancreatic cancer.

of pancreatic cancer cells [Figure 1A (e,f)]. SMA expression was also observed in the stroma region of pancreatic cancer cells expressing FAP $\alpha$ [Figure $1 A(\mathrm{~g}, \mathrm{~h})]$. In pancreatic cancer tissues, FAP $\alpha$ was lowly expressed in 22 cases and highly expressed in 34 cases. In the paracancerous tissues, FAP $\alpha$ was lowly expressed in 52 cases and highly expressed only in 4 cases. The FAP $\alpha$ expression in pancreatic cancer tissues was significantly higher than that in adjacent tissues, and the difference was statistically significant $(\mathrm{P}<0.0001$; Figure $1 B)$.

\section{Relationship between the FAP expression level and pathological features in buman pancreatic cancer}

The immunohistochemical staining of FAP $\alpha$ was analyzed to compare the relationship between the expression level of $\mathrm{FAP} \alpha$ protein and pathological features in pancreatic cancer 
Table 1 Relationship between expression of FAPa protein and pathological features in pancreatic cancer

\begin{tabular}{|c|c|c|c|c|}
\hline \multirow{2}{*}{$\begin{array}{l}\text { Pathological } \\
\text { features }\end{array}$} & \multirow{2}{*}{$\begin{array}{l}\text { Number } \\
\text { of cases }\end{array}$} & \multicolumn{2}{|c|}{$\mathrm{FAP} \alpha$} & \multirow[b]{2}{*}{$P$ value } \\
\hline & & $\begin{array}{c}\text { Low } \\
\text { expression }\end{array}$ & $\begin{array}{c}\text { High } \\
\text { expression }\end{array}$ & \\
\hline Age & & & & 0.645 \\
\hline$<65$ & 37 & 16 & 21 & \\
\hline$>65$ & 19 & 7 & 12 & \\
\hline Sex & & & & 0.884 \\
\hline Male & 31 & 13 & 18 & \\
\hline Female & 25 & 10 & 15 & \\
\hline Tumor site & & & & 0.903 \\
\hline Head & 36 & 15 & 21 & \\
\hline Body/tail & 20 & 8 & 12 & \\
\hline $\begin{array}{l}\text { Surgical } \\
\text { methods }\end{array}$ & & & & 0.947 \\
\hline PD & 33 & 14 & 19 & \\
\hline DP & 20 & 8 & 12 & \\
\hline TP & 3 & 1 & 2 & \\
\hline $\begin{array}{l}\text { Histological } \\
\text { grade }\end{array}$ & & & & 0.530 \\
\hline $1 / 2$ & 32 & 12 & 20 & \\
\hline 3 & 24 & 11 & 13 & \\
\hline $\begin{array}{l}\text { T classification } \\
\text { (7th) }\end{array}$ & & & & 0.183 \\
\hline $\mathrm{T} 1 / \mathrm{T} 2$ & 10 & 6 & 4 & \\
\hline T3/T4 & 46 & 17 & 29 & \\
\hline Lymph node & & & & $0.038^{\star}$ \\
\hline- & 26 & 14 & 12 & \\
\hline+ & 30 & 8 & 22 & \\
\hline $\begin{array}{l}\text { Distant } \\
\text { metastasis }\end{array}$ & & & & 0.071 \\
\hline- & 51 & 23 & 28 & \\
\hline+ & 5 & 0 & 5 & \\
\hline $\begin{array}{l}\text { TNM staging } \\
\text { (7th) }\end{array}$ & & & & 0.288 \\
\hline $1 / I I$ & 10 & 6 & 4 & \\
\hline III/IV & 46 & 17 & 29 & \\
\hline
\end{tabular}

*, P<0.05. PD, pancreaticoduodenectomy; DP, distal pancreatectomy; TP, total pancreatectomy. tissues. The results suggested that higher $\mathrm{FAP} \alpha$ protein expression in pancreatic cancer tissues was associated with positive lymph node metastasis $(\mathrm{P}=0.038$; Table 1$)$.

\section{The FAP expression level is associated with overall survival in patients with pancreatic cancer}

Patients with high FAP $\alpha$ expression (mean survival time: 13 months; 95\% confidence interval: 9.31-18.69 months) had a shorter survival time than those with low FAP $\alpha$ expression (median survival time: 34 months; $95 \%$ confidence interval: 8.84-59.16 months; Figure 1C, log-rank test; $\mathrm{P}=0.044<0.05)$. Univariate and multivariate analyses (Cox regression model) were used to investigate the effects of the FAP $\alpha$ expression levels and clinicopathological features on the overall survival of patients. The results showed that the FAP $\alpha$ expression level is an independent risk factor for the prognosis of patients with pancreatic cancer. High FAP $\alpha$ expression indicated a poor prognosis in patients with pancreatic cancer (Table 2; $\mathrm{P}<0.05)$.

\section{Human primary PSC identification and culture}

Human primary PSCs were successfully isolated using the outgrowth method. Under light microscopy, PSCs were star shaped [Figure $2 A$ (a)]. The relative specific markers of PSCs were detected by immunofluorescence staining. Human primary PSCs expressed SMA, Desmin, and GFAP [Figure $2 A(\mathrm{~b}, \mathrm{c}, \mathrm{d})](19)$.

\section{Pancreatic cancer cells induce FAPa expression in PSCs in vitro}

Flow cytometry and immunofluorescence were used to detect FAP $\alpha$ expression in human primary PSCs in adjacent tissues. The results suggested that the FAP $\alpha+$ cell ratio in human primary PSCs in six adjacent tissues is $0.98 \% \pm 0.98 \%$. No FAP $\alpha$ expression was detected, a finding that was consistent with the result of immunofluorescence assay [Figure $2 B$; Figure $2 C$ (a)]. When TGF- $\beta 1$ was added to the different media, FAP $\alpha$ expression in human primary PSCs was significantly induced [Figure $2 C(\mathrm{~b}, \mathrm{c})$; Figure $2 \mathrm{D}(\mathrm{a})]$. The neutralizing antibodies to TGF $\beta$ reduced FAP $\alpha$ expression [Figure 2C (d); Figure 2D (b)]. TGF $\beta 1$ expression in BxPC3, Capan1, and PANC1 CM (BxPC3:

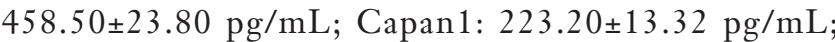
PANC1: $360.00 \pm 10.93 \mathrm{pg} / \mathrm{mL}$ ) was significantly higher 
Table 2 Univariate and multivariate analysis of items on overall survival of pancreatic cancer patients

\begin{tabular}{|c|c|c|c|c|}
\hline Variable & \multicolumn{2}{|c|}{ Univariate analysis } & \multicolumn{2}{|c|}{ Multi-factor analysis } \\
\hline \multicolumn{5}{|l|}{ Sex } \\
\hline Male vs. female & $0.968(0.458-2.049)$ & 0.932 & & \\
\hline \multicolumn{5}{|l|}{ Age (year) } \\
\hline \multicolumn{5}{|l|}{ Tumor site } \\
\hline Head vs. body/tail & $1.755(0.808-3.811)$ & 0.155 & & \\
\hline \multicolumn{5}{|l|}{ Histological grade } \\
\hline $1 / 2$ vs. 3 & $1.182(0.548-2.551)$ & 0.669 & & \\
\hline \multicolumn{5}{|l|}{ Lymph node } \\
\hline$-v s .+$ & $0.920(0.412-2.054)$ & 0.838 & & \\
\hline \multicolumn{5}{|l|}{ Distant metastasis } \\
\hline$-v s .+$ & $0.212(0.073-0.614)$ & 0.004 & $0.240(0.082-0.702)$ & 0.009 \\
\hline \multicolumn{5}{|l|}{ TNM staging } \\
\hline I/II vs. III/IV & $0.986(0.391-2.486)$ & 0.976 & & \\
\hline \multicolumn{5}{|l|}{$\mathrm{FAP} \alpha$} \\
\hline Low vs. high expression & 3.629 (1.479-8.904) & 0.005 & $3.013(1.240-7.319)$ & 0.015 \\
\hline
\end{tabular}

than that in human primary PSCs $(\mathrm{P}<0.001$; Figure $2 E)$.

\section{Effects of FAPa+ and FAPa-PSCs on pancreatic cancer cell proliferation}

The effects of FAP $\alpha+$ and FAP $\alpha-$ PSCs on the proliferation of BxPC3, Capan1, and PANC1 were detected by the CCK8 method. Both FAP $\alpha+$ and FAP $\alpha-$ PSCs promoted BxPC3, Capan1, and PANC1 proliferation, and the difference was statistically significant $(\mathrm{P}<0.05$; Figure $3 A)$. However, $\mathrm{BxPC} 3$, Capan1 and PANC1 proliferation in the coculture of either FAP $\alpha+$ PSCs or FAP $\alpha$ - PSCs showed no significant differences $(\mathrm{P}>0.05$; Figure $3 A)$. The tumor growth of nude mice in different groups was compared. Compared with BxPC3 and PANC1 cells alone, both FAP $\alpha+$ and FAP $\alpha-$ PSCs can promote the growth of $\mathrm{BxPC} 3$ and PANC1 xenografts $(\mathrm{P}<0.05)$. However, the effects of FAP $\alpha+$ and $\mathrm{FAP} \alpha-\mathrm{PSCs}$ to promote the growth of pancreatic cancer were not significantly different $(\mathrm{P}>0.05$; Figure $3 B)$.
Effects of FAPa+ and FAPa-PSCs on pancreatic cancer cell migration

The effects of FAP $\alpha+$ and FAP $\alpha-$ PSCs on BxPC3, Capan1, and PANC1 migration were examined by Transwell experiments. The effects of FAP $\alpha+$ and FAP $\alpha-$ PSCs on BxPC3, Capan1, and PANC1 migration were compared. The results suggested that, compared with FAP $\alpha-\mathrm{PSCs}$, FAP $\alpha+$ PSCs significantly promoted BxPC3, Capan1, and PANC1 migration, and the difference was statistically significant $(\mathrm{P}<0.05)$. PT100 inhibited the effect of FAP $\alpha+\mathrm{PSCs}$ on BxPC3, Capan1, and PANC1 migration (Figure 3C).

\section{Effects of FAP + and FAP $\alpha-P S C$ s on pancreatic cancer cell invasion}

The effects of FAP $\alpha+$ and FAP $\alpha$ - PSCs on the invasion of pancreatic cancer cells (BxPC3, Capan1, and PANC1) were analyzed using the Transwell assay. The results suggested 
A
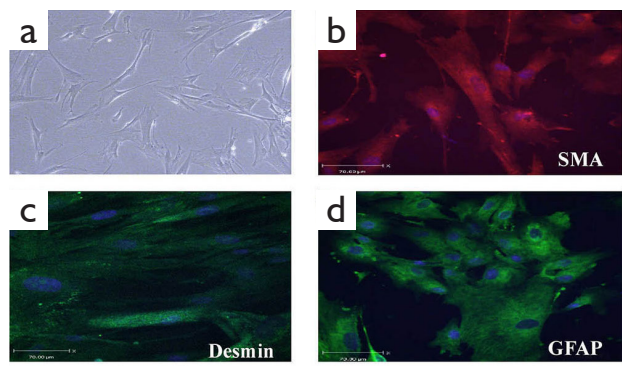

B

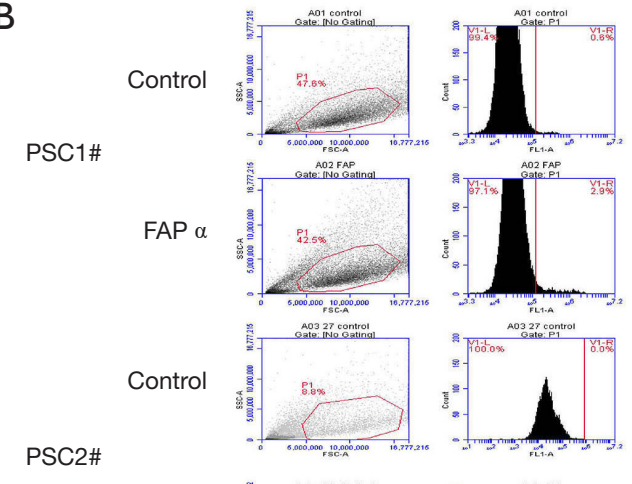

FAP $\alpha$
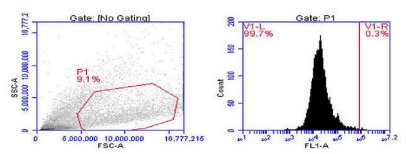

Contro

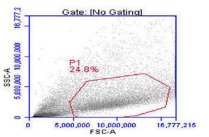

FAP $\alpha$
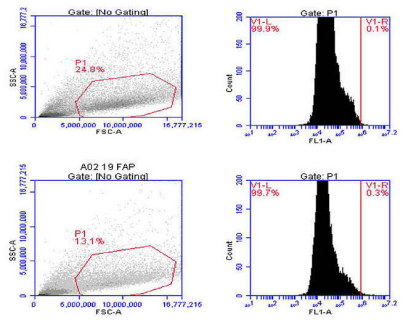

PSC3\#

$\mathrm{D}$

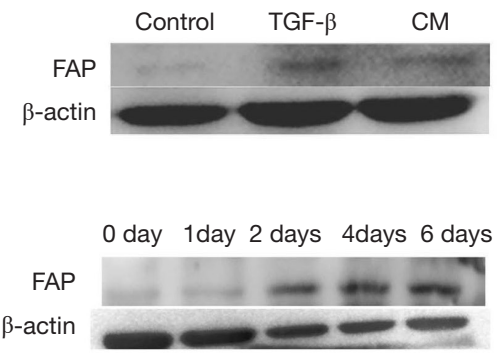

C
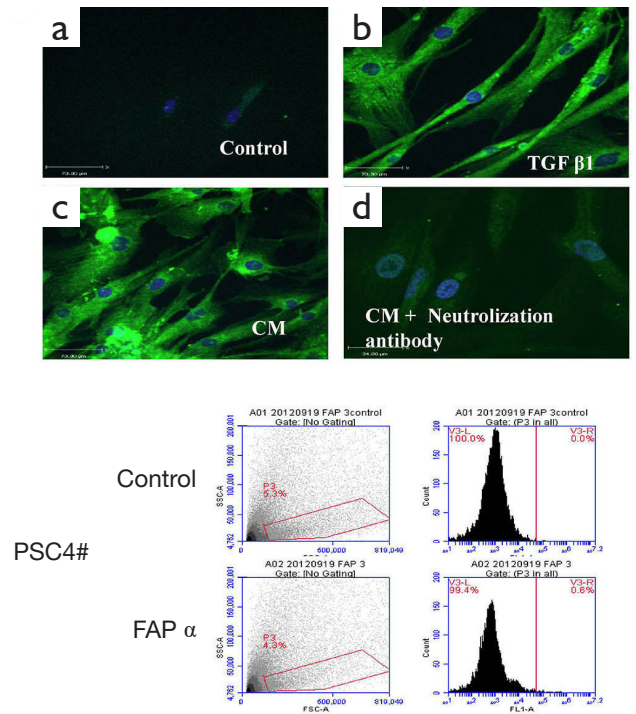

Control
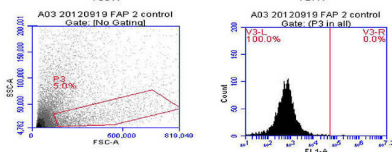

PSC5\#
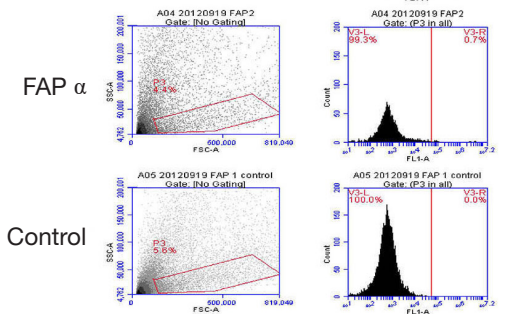

FAP $\alpha$
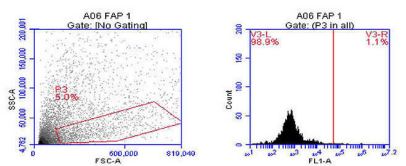

$\mathrm{E}$

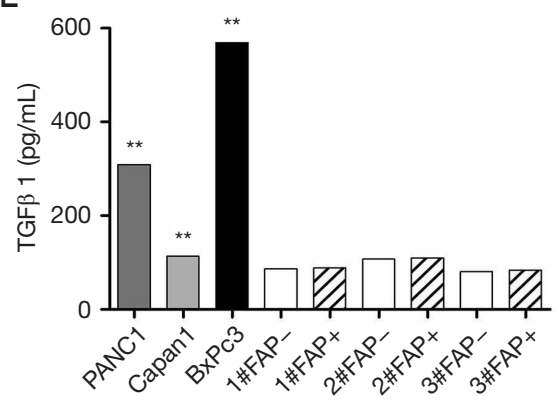

Figure 2 Human pancreatic cancer cells induce FAP $\alpha$ expression in PSCs in vitro by TGF $\beta 1$. (A) Human primary PSC isolation and identification. a: Human primary PSC morphology under optical field of view (magnification, 200x). Immunofluorescence was used to detect SMA (b), Desmin (c), and GFAP expression (d) in human PSCs; scale: $70 \mu \mathrm{m}$; (B) flow cytometry was used to detect the proportion of FAP $\alpha+$ PSCs; (C) immunofluorescence assay was used to detect FAP $\alpha$ expression in human PSCs under different conditions: a—control group; b-TGF $\beta$ added to medium; c — conditioned medium (CM) added to pancreatic cancer cells; d-neutralizing antibodies to TGF $\beta 1$ were added to CM; (D) after adding human primary PSCs in medium containing TGF $\beta 1(10 \mathrm{ng} / \mathrm{mL})$ for 2 days, FAP $\alpha$ expression is significantly induced in human primary PSCs; (E) ELISA was used to detect TGF $\beta 1$ expression in pancreatic cancer cells and six human primary stellate cells. ${ }^{*}, \mathrm{P}<0.001$. 
A

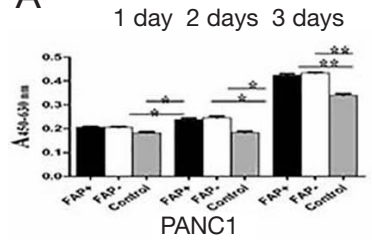

1 day 2 days 3 days
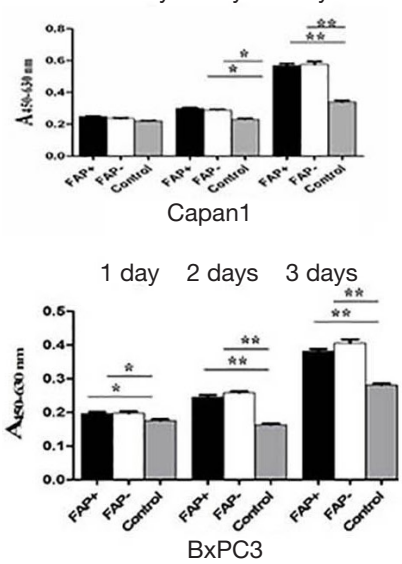

B

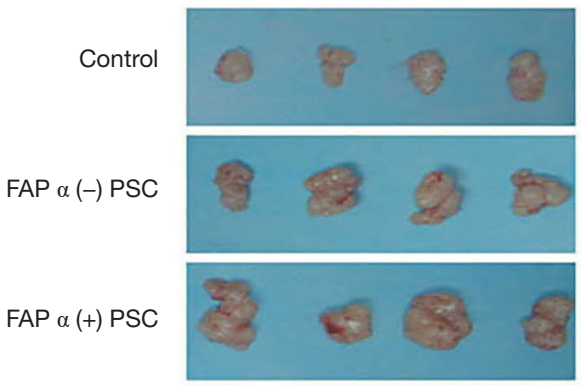

PANC1

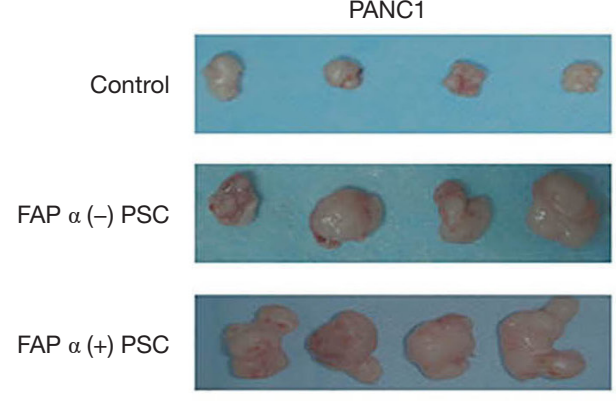

C

Control

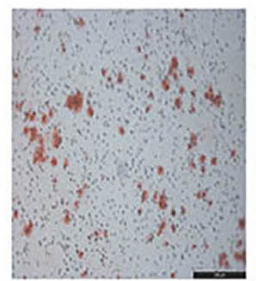

PANC1

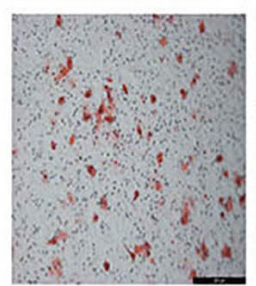

Capan1

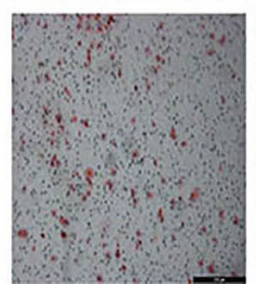

FAP $\alpha(-)$ PSCs
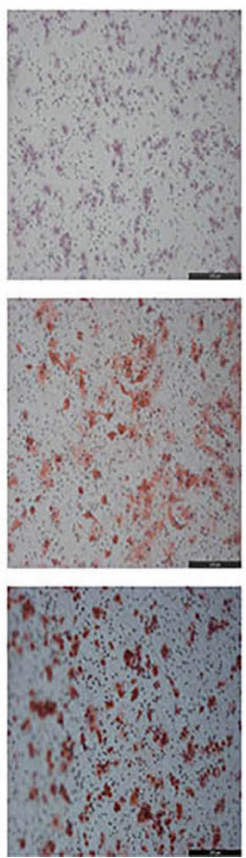

FAP $\alpha(+)$ PSCs
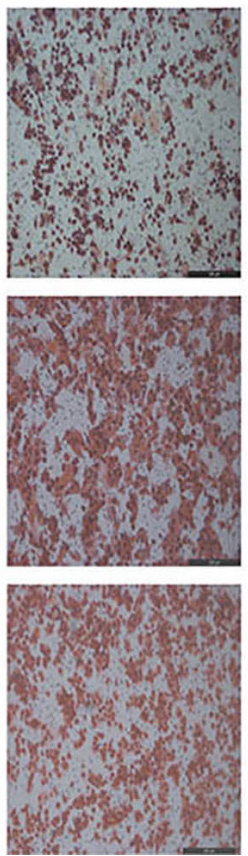

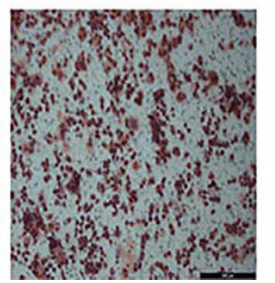

FAP $\alpha(+)$ PSCs + PT100
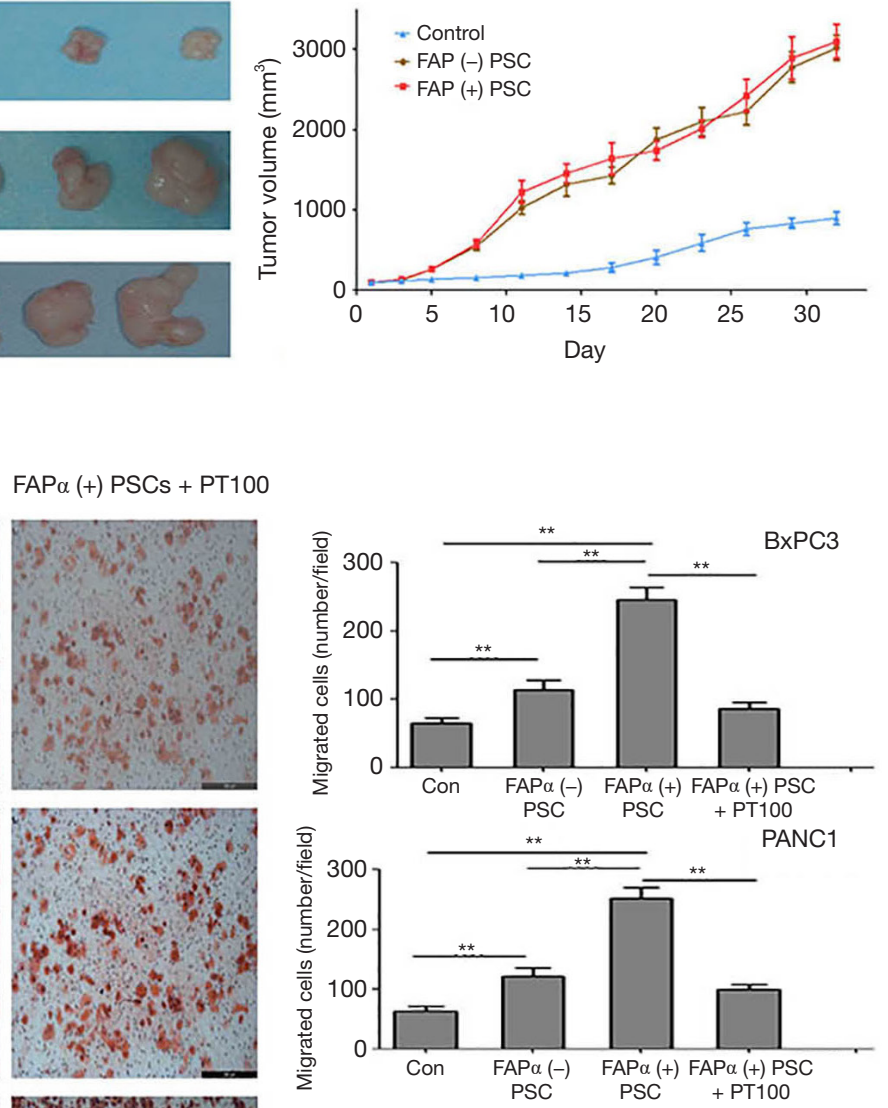

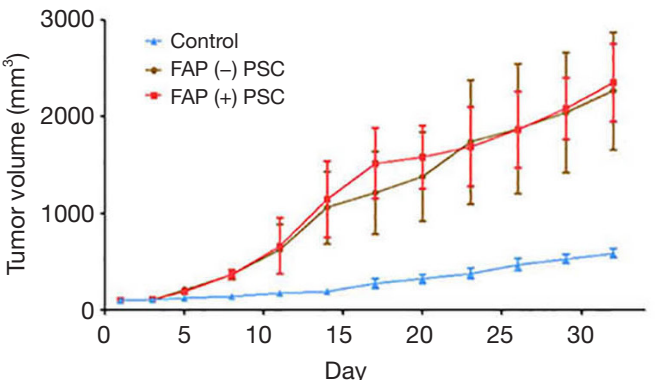

Day

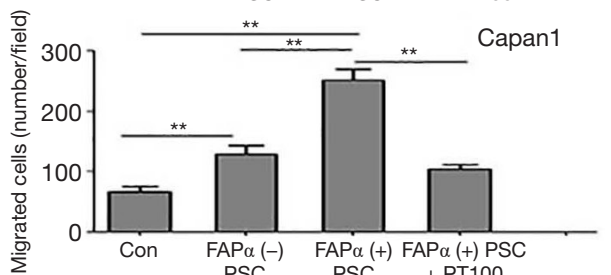

Figure 3 Human $\mathrm{FAP} \alpha(+)$ PSCs promote the migration of pancratic cancer cells in vitro. (A) Effects of FAP $\alpha+$ and FAP $\alpha$ - pancreatic stellate cells on the proliferation of pancreatic cancer cells; (B) effects of FAP $\alpha+$ and $\mathrm{FAP} \alpha$ - pancreatic stellate cells on the proliferation of subcutaneous xenografts (BxPC3 and PANC1) in nude mice; (C) effects of FAP $\alpha+$ and FAP $\alpha$ - PSC on BxPC3, PANC1, and Capan1 migration. *, $\mathrm{P}<0.05 ;{ }^{* *}, \mathrm{P}<0.001$. 
that both FAP $\alpha+$ and FAP $\alpha$ - PSCs can promote the invasion of pancreatic cancer cells compared with the control group. Compared with FAP $\alpha$ - PSCs, FAP $\alpha+$ PSCs significantly promoted $\mathrm{BxPC} 3$, Capan1, and PANC1 invasion, and the difference was statistically significant $(\mathrm{P}<0.05$; Figure 4A). PT100 reduced the effect of FAP $\alpha+$ PSCs on BxPC3, Capan1, and PANC1 invasion $(\mathrm{P}<0.05$; Figure $4 A)$. Both FAP $\alpha+$ and FAP $\alpha-$ PSCs promoted PANC1 invasion and metastasis to nude mouse liver compared with the PANC1 alone group, and the difference was statistically significant $(\mathrm{P}<0.05)$. FAP $\alpha+\mathrm{PSCs}$ showed stronger potential to promote PANC1 invasion to nude mouse liver and formed more metastases than FAP $\alpha$ - PSCs; Additionally, the difference was statistically significant $(\mathrm{P}<0.05)$. PT100 reduced the ability of FAP $\alpha+$ PSCs to promote PANC1 invasion and metastasis $(\mathrm{P}<0.05$; Figure $4 B)$.

The cytokine chip detects differential cytokines expressed by FAPa+ and FAPa-PSCs

The cytokines expressed by FAP $\alpha+$ and FAP $\alpha$ - PSCs were detected using the RayBio's human cytokine chip. FAP $\alpha+$ PSCs highly expressed cytokines, including GRO- $\alpha$ (CXCL1), MCP-3, IL-7, VEGF, GCP-2, eotaxin, and osteoprotegerin, compared with FAP $\alpha$ - PSCs. Among the highly expressed differential cytokines, CXCL1, which had the most frequent increase and significant difference (35.88-fold), was selected as the cytokines for subsequent study (Figure $5 A, B$ ).

\section{ELISA for the differential expression of cytokines expressed by FAP + and FAP $\alpha-P S C s$}

Six human primary PSCs (PSC3\#, PSC4\#, PSC5\#, PSC6\#, PSC7\#, and PSC8\#) were cultured with DMEM/F12 medium with or without TGF $\beta 1$. The cell supernatants of FAP $\alpha+$ and FAP $\alpha$ - PSCs were collected for CXCL1 detection. The results showed that FAP $\alpha+$ PSCs highly expressed CXCL1 in five human primary PSCs (i.e., PSC3\#, PSC4\#, PSC5\#, PSC6\#, and PSC7\#), and the difference was statistically significant $(\mathrm{P}<0.0001$; Figure 5C). The results showed that the cytokine CXCL1 receptor CXCR2 was expressed in the eight pancreatic cancer cell lines (Figure 5D).

\section{The phosphotyrosine kinase receptor protein chip detects differentially expressed proteins in pancreatic cancer cells under the influence of FAP $\alpha+$ or FAPa-PSCs}

The following phosphorylated tyrosine kinase receptors of
BxPC3 cocultured with FAP $\alpha+$ PSCs were highly expressed compared with those cocultured with FAP $\alpha$ - PSCs: JAK3, EphB1, ZAP70, LCK, IGF-1R, Btk, ErbB3, EphA5, NGFR, POR2, EphA3, JAK2, ALK, MUSK, SYK, FGFR2, SRNS, Tie-2, RYK, EphA2, BMX, TRKB, EphA8, and VEGFR3 (Figure 6A). The following phosphorylated tyrosine kinase receptors of PANC1 cocultured with FAP $\alpha+$ PSCs were highly expressed compared with those cocultured with FAP $\alpha$ - PSCs: EphA4, FAK, and EphB3 (Figure 6B). Based on the cluster analysis of differential proteins and degree of significance, a differentially phosphorylated tyrosine kinase receptor protein, EphB1 (Figure 6C), was highly expressed by $\mathrm{BxPC} 3$, and a differentially phosphorylated tyrosine kinase receptor protein, EphB3 (Figure 6D), which was highly expressed by PANC1, were selected as proteins for subsequent follow-up studies.

\section{Interaction of differentially expressed phosphorylated tyrosine kinase receptor proteins with differential cytokine receptors}

The expression of EphB1 and EphB3, in eight pancreatic cancer cell lines (i.e., AsPc1, BxPC3, Capan1, MIAPaCa-2, PANC1, SW1990, Su86.86, and T3M4) were confirmed by Western blotting (Figure $7 A$ ). After incubating $\mathrm{BxPC} 3$ and PANC1 in medium containing CXCL1 $(10 \mathrm{ng} / \mathrm{mL})$ for $30 \mathrm{~min}$, the interactions of CXCR2, EphB1 and EphB3 were detected by co-IP. An interaction was found between CXCR2 and EphB1 in BxPC3 cells. In PANC1 cells, an interaction relationship was also found between CXCR2 and EphB3 (Figure 7B). BxPC3 and PANC1 were stimulated with CXCL1, EphrinB1, and EphrinB3 fusion proteins. The effects of CXCL1, EphrinB1, and EphrinB3 on the Akt signaling pathway were detected by Western blotting. The results suggested that CXCL1, EphrinB1, and EphrinB3 can promote the Akt phosphorylation of BxPC3 and PANC1. CXCL1, EphrinB1, and EphrinB3 also synergistically promoted Akt phosphorylation (Figure 7C). Using Transwell migration and invasion experiments, we added the Transwell lower chamber to the prepared medium (DMEM/high-glucose or RPMI1640 medium containing $0.5 \%$ BSA, $10 \mathrm{mM} \mathrm{HEPES}$ ), medium+CXCL1 $(10 \mathrm{ng} / \mathrm{mL})$, and medium+EphrinB1Fc or EphrinB3-Fc $(1 \mu \mathrm{g} / \mathrm{mL})$. The medium + CXCL1 $(10 \mathrm{ng} / \mathrm{mL})+$ EphrinB1-Fc or EphrinB3-Fc $(1 \mu \mathrm{g} / \mathrm{mL})$ was used to examine the effects of CXCL1, EphrinB1, CXCL1, and EphrinB3 on BxPC3 and PANC1 migration and invasion. The results showed the following: (I) CXCL1 

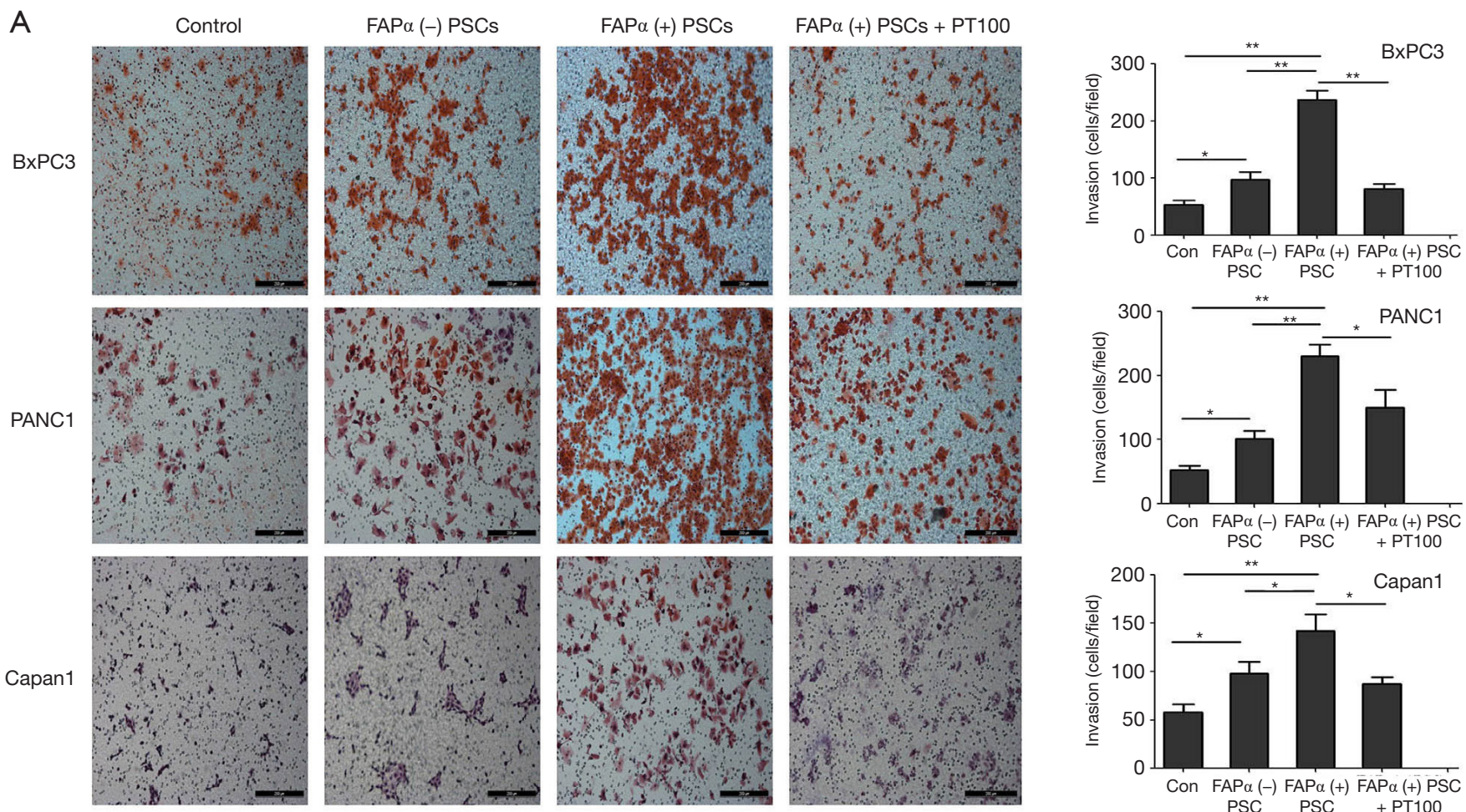

B
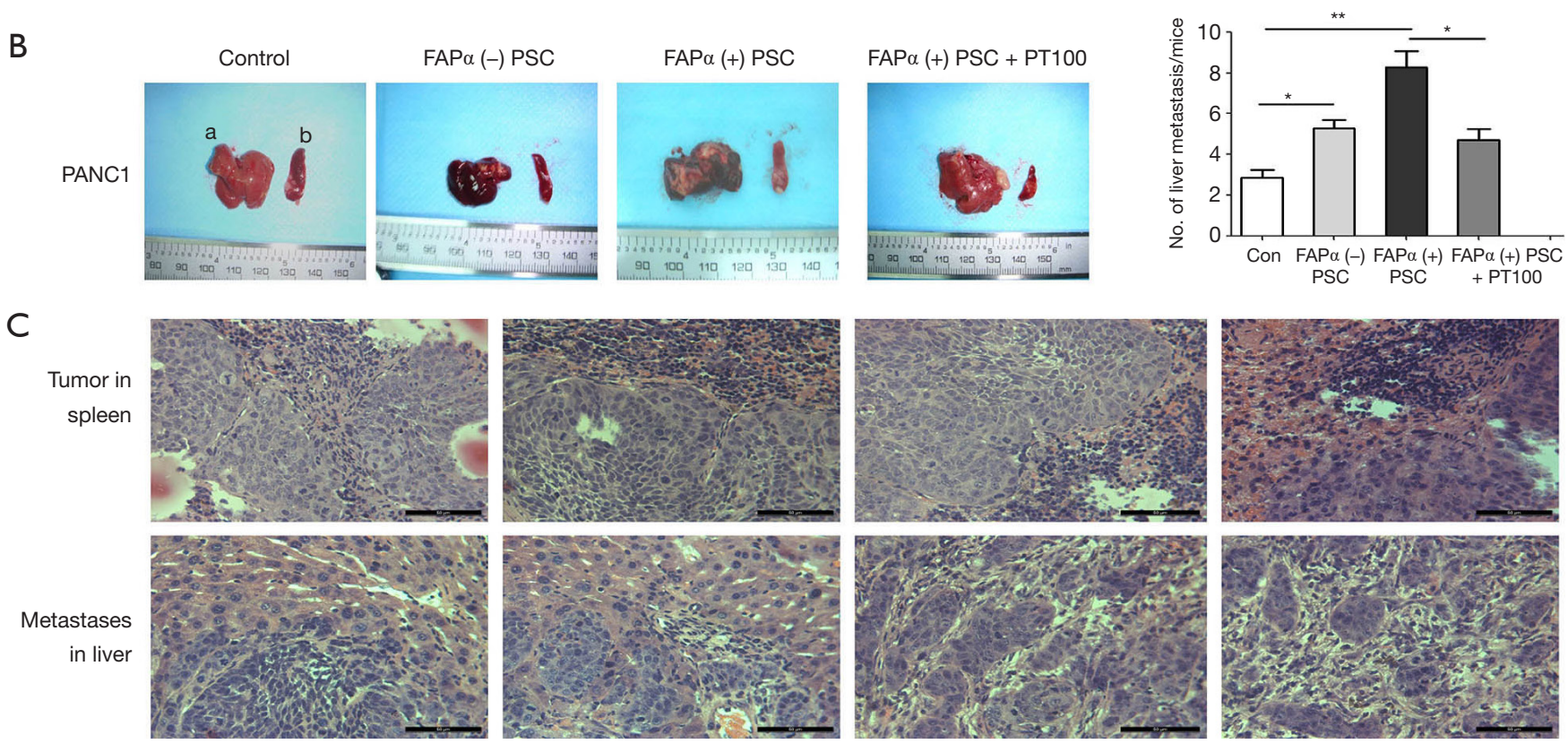

Figure 4 Human FAP $\alpha(+)$ PSCs promote invasion and metastasis of pancreatic cancer. (A) Effects of FAP $\alpha+$ and FAP $\alpha$ - pancreatic stellate cells on BxPC3, PANC1, and Capan1 invasion; (B) infection of pancreatic cancer cells PANC1, FAP $\alpha+$ PSCs, and FAP $\alpha-$ PSCs into nude mice spleen to establish a liver metastasis model; (a) General scheme. (b) Comparison of the effects of FAP $\alpha+$ and FAP $\alpha$ - pancreatic stellate cells on PANC1 invasion and metastasis in vivo; (C) Masson staining of the spleen tumor and liver metastasis. *, $\mathrm{P}<0.05$; **, $\mathrm{P}<0.001$. 
A
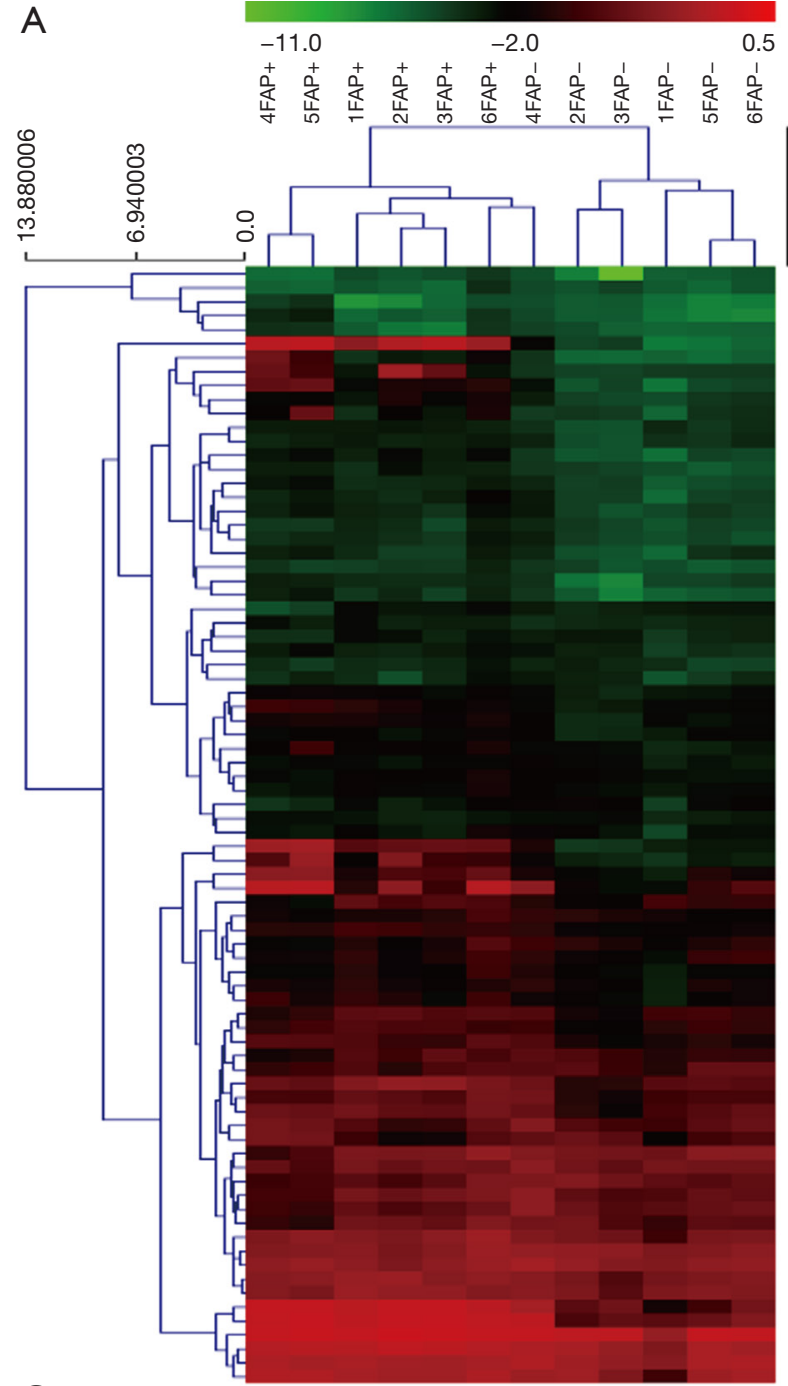

C

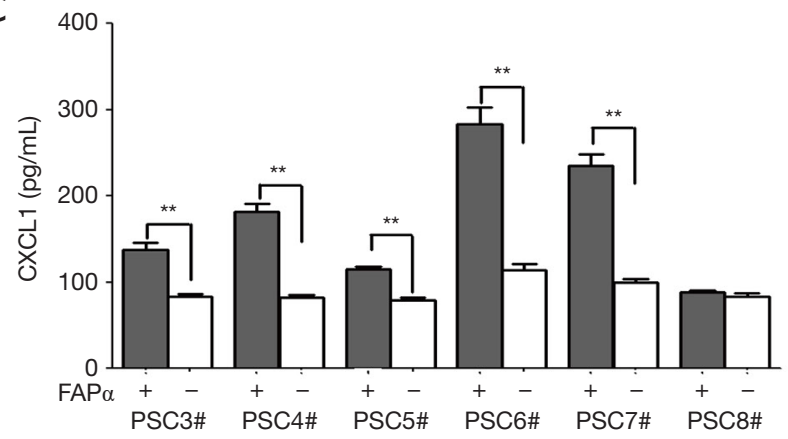

B
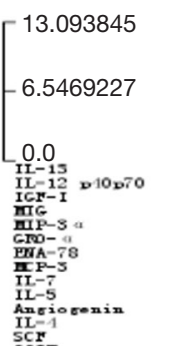

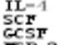

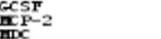

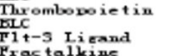
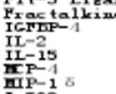

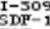

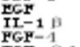
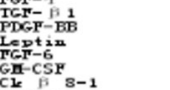

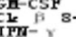

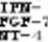

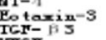

更

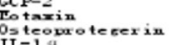

${ }_{1 \mathrm{~T}-1}$
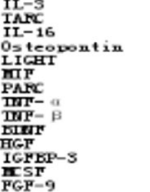

TSF
PGG-9
IF-10
ITFM-2

TTr-3

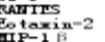

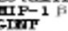

oncos

$\mathrm{IP}_{\mathrm{CH}-\mathrm{B}} 2$

1
$15-8$

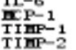

D

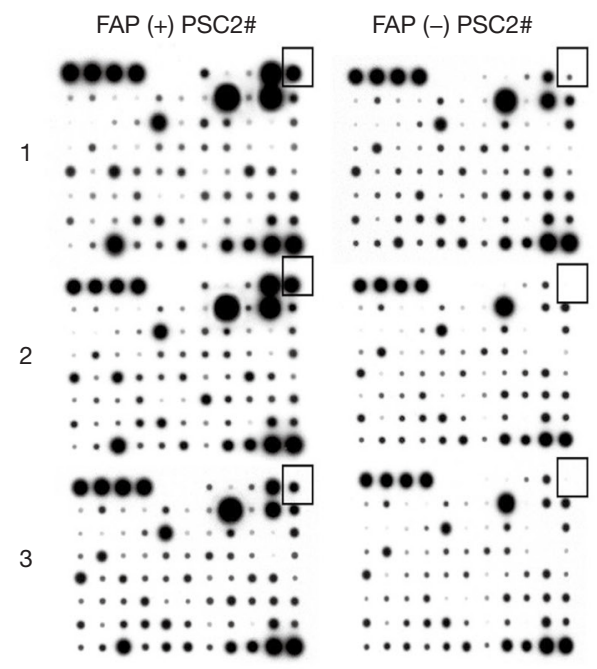

CXCL2

$\beta$ actin

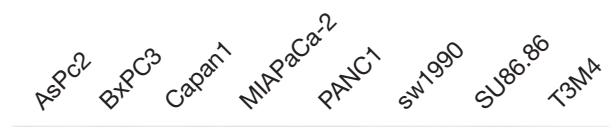

Figure 5 Human FAP $\alpha(+)$ PSCs and pancreatic cancer cells express high level of CXCL1, CXCR2, respectively. (A) Cluster analysis of the differential expression of cytokines in FAP $\alpha+$ and FAP $\alpha$-PSCs; (B) RayBio human cytokine chip detected differential cytokines expressed by FAP $\alpha+$ and FAP $\alpha-$ PSCs (PSC1\# and PSC2\#). FAP $\alpha+$ PSCs highly expressed CXCL1 compared with FAP $\alpha$ - pancreatic stellate cells. The black box was identified as the chip detection site of CXCL1; (C) enzyme-linked immunosorbent assay showed that FAP $\alpha+$ PSCs highly expressed CXCL1 in different human primary PSCs; (D) Western blotting was used to detect the expression of CXCR2 in 8 pancreatic cancer cell lines. ${ }^{* *}, \mathrm{P}<0.0001$. 


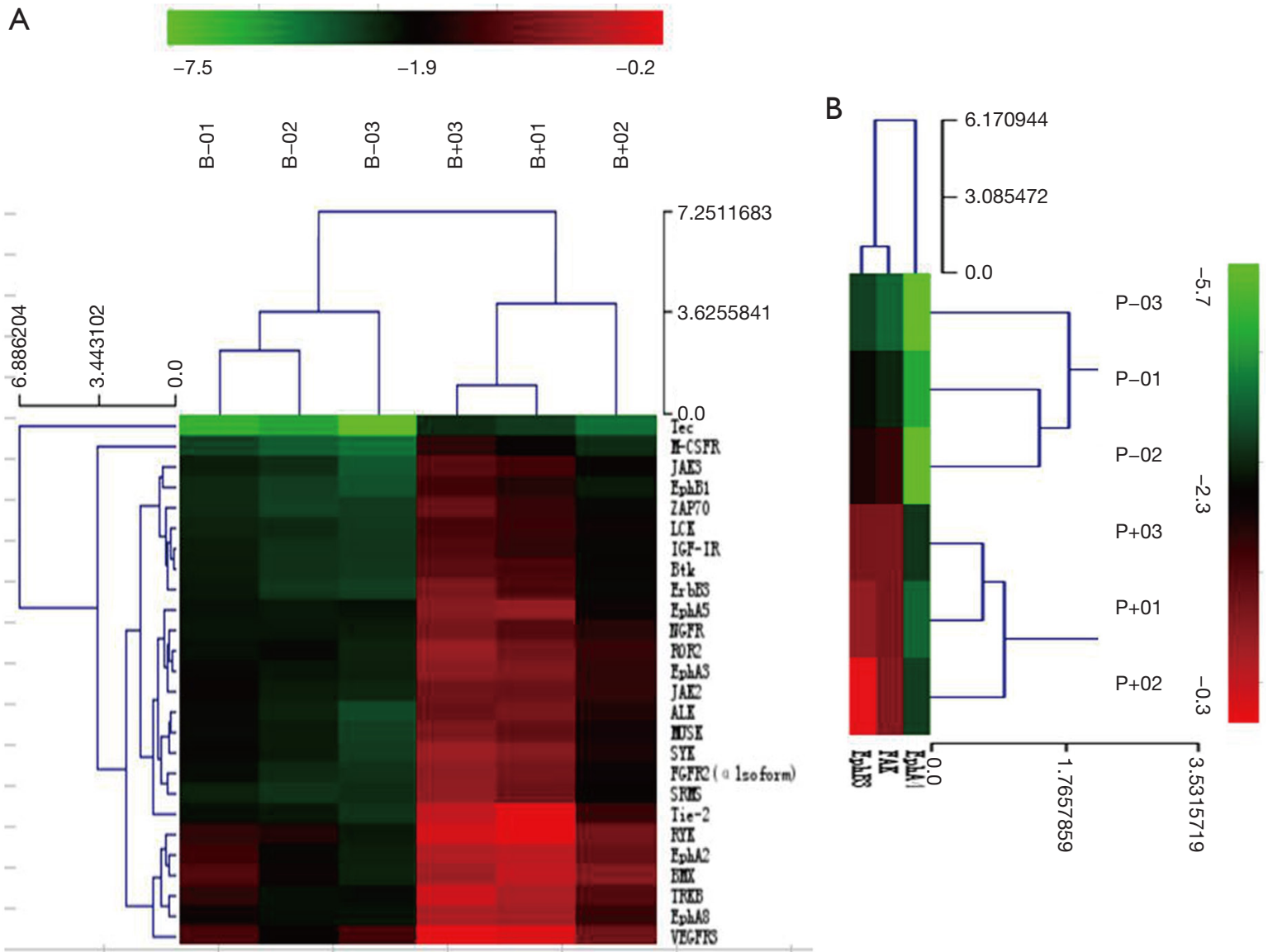

C

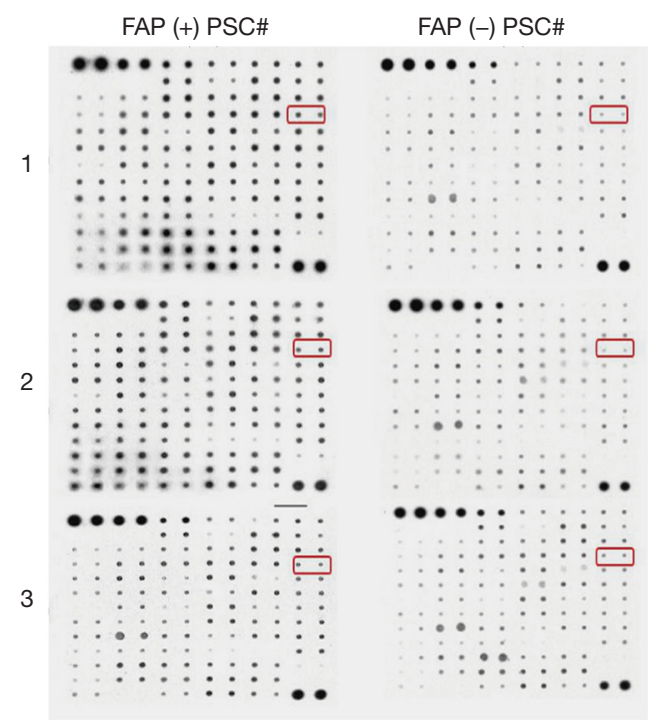

D

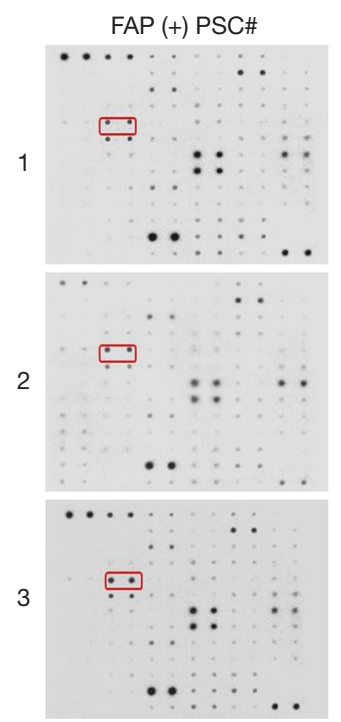

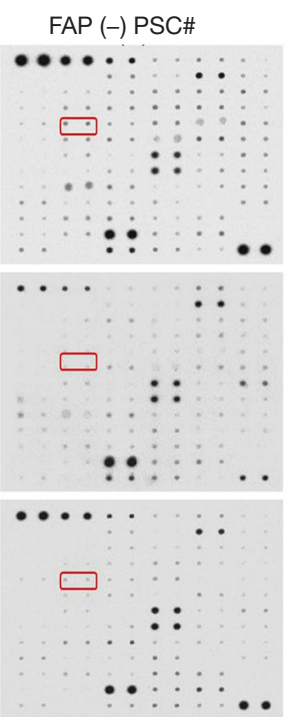

Figure 6 Human FAP $\alpha(+)$ PSCs induce EphB1 and EphB3 of pancreatic cancer. (A) RayBio human phosphotyrosine kinase receptor microarray assay for differentially phosphorylated tyrosine kinase receptor protein clustering analysis of BxPC3 (A) and PANC1 (B) expression under the influence of FAP $\alpha+$ or FAP $\alpha$ - pancreatic stellate cells. The differentially phosphorylated tyrosine kinase receptor protein EphB1 (indicated by the red box) was expressed by BxPC3 (C) and PANC1 (D) under the influences of FAP $\alpha+$ and FAP $\alpha-$ pancreatic stellate cells, respectively. 
A

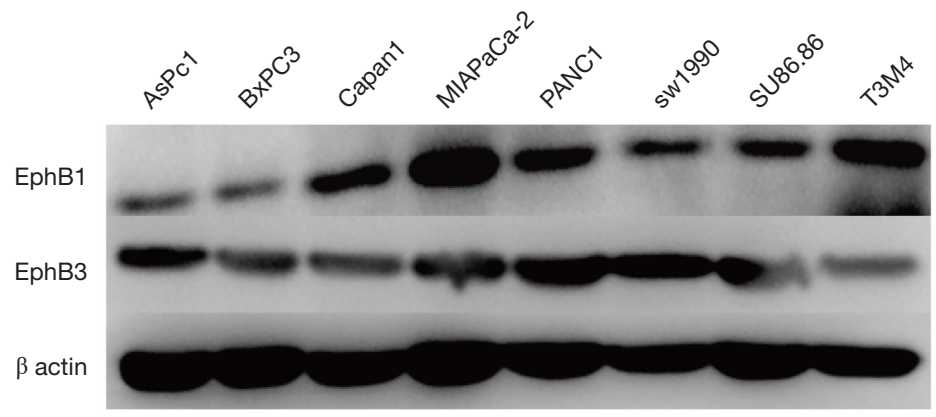

B

BXPC3

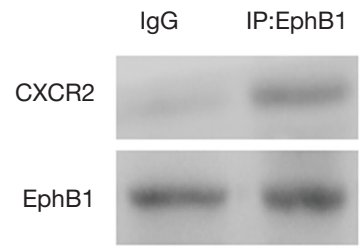

BxPC3

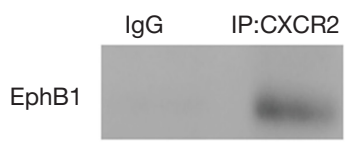

CXCR2

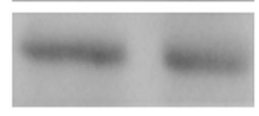

C

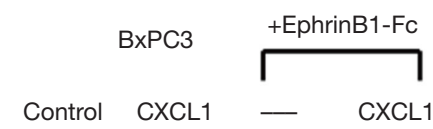

pAkt

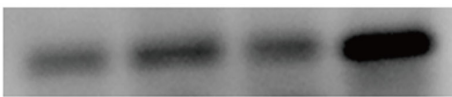

Akt

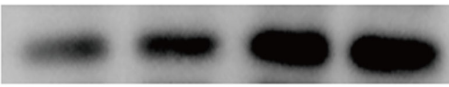

$\mathrm{D}$
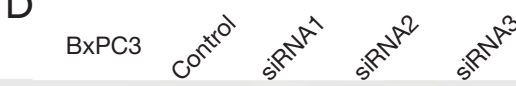

EphB1

$\beta$ actin
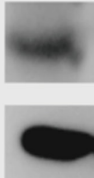

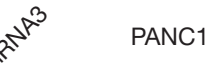

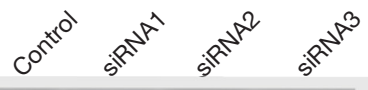

EphB3

$\beta$ actin
PANC1

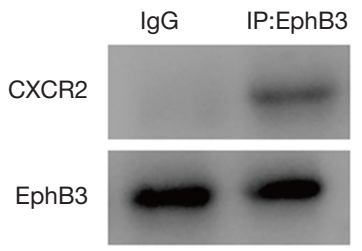

PANC1

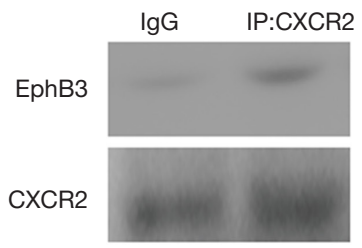

PANC1

Control CXCL1 - CXCL1
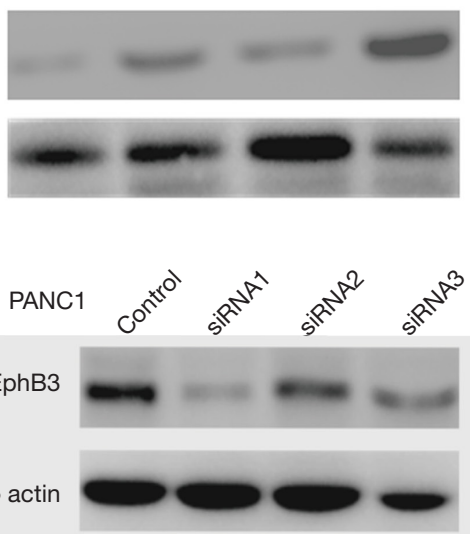

Figure 7 Interactions between CXCR2 AND EphB1 or EphB3 of pancreatic cancer cells activate Akt signaling. (A) Western blot analysis of the expression of the tyrosine kinase receptors EphB1 and EphB3 in eight pancreatic cancer cells; (B) immunoprecipitation and Western blot analysis of the interaction between differentially expressed phosphorylated tyrosine kinase receptor proteins and differential cytokine receptors. Interaction relationship between CXCR2 and EphB1 in the pancreatic cancer cell line BxPC3. Interaction between CXCR2 and EphB3 in the pancreatic cancer cell line PANC1; (C) effects of CXCL1, EphrinB1, and EphrinB3 on Akt signaling; (D) EphB1 and EphB3 protein expression after siRNA interference with BxPC3 EphB1 and PANC1 EphB3 receptors. 
and EphrinB1 can promote the migration and invasion of BxPC3; the application of siRNA to interfere with EphB1 expression (Figure 7D) reduced the effect of EphrinB1 on the migration and invasion of $\mathrm{BxPC} 3$, and both CXCL1 and EphrinB1 synergistically promoted the effects of the migration and invasion of BxPC3 (Figure 8A,B); (II) the application of siRNA to interfere with EphB3 expression reduced the effect of EphrinB3 on PANC1 migration and invasion, and CXCL1 and EphrinB3 synergistically promoted the effects of PANC1 migration and invasion (Figure 8C,D).

\section{Discussion}

$\mathrm{FAP} \alpha$ dissolves collagen and gelatin, thereby degrading the extracellular matrix, suggesting that FAP $\alpha$ plays an important role in the formation and maintenance of the tumor extracellular matrix $(20,21)$. FAP $\alpha$ also has the activity of dipeptidyl peptidase to cleave and alter the specificity of certain peptide hormones and chemical factor receptors (22). FAP $\alpha$ is selectively expressed in embryonic tissues, physiologically reconstructed organs, wound healing, and malignant tumor-associated myofibroblasts, such as colorectal, ovarian, breast, bladder, and lung malignancies $(23,24)$. FAP $\alpha$ has also been associated with growth, invasion, metastasis, and angiogenesis in epithelialderived malignancies $(16,25,26)$. Cheng et al. (27) reported that FAP $\alpha$ promotes the growth of human embryonic kidney 293 cells in mice. Inhibiting FAP $\alpha$ activity can also slow the growth of FAP $\alpha$ expression-positive tumors in a colon cancer xenograft model. Henry et al. (16) found that patients with high FAP $\alpha$ expression in colon cancer have a worse prognosis and are more likely to metastasize or recur. Our study found that FAP $\alpha$ was highly expressed in pancreatic cancer stroma. The expression of FAP $\alpha$ in the interstitial region adjacent to pancreatic cancer cells was also higher than that in the interstitial region away from pancreatic cancer cells. FAP $\alpha$ expression was also related to lymph node metastasis. Patients with high FAP $\alpha$ expression had a short survival and poor prognosis. FAP $\alpha+$ PSCs showed more potential to promote the migration, invasion, and metastasis of pancreatic cancer cells compared with FAP $\alpha$ - PSCs.

Talabostat has been applied to phase II clinical trials in patients with advanced colorectal cancer. The results showed that $21 \%$ of patients were under control (14). This molecular drug with low cytotoxicity is cross-linked with a targeting polypeptide to shield the active site of FAP $\alpha$ to form a temporarily inactive prodrug. This prodrug is infused into the body and delivered to the tumor in an inactive form, and then it is activated to release the active parent drug against FAP $\alpha$ (15). Studies have also been conducted to inhibit tumorigenesis by modulating FAP $\alpha$-mediated downstream signaling. Gonzalez-Gronow et al. (28) found that plasminogen binding to FAP $\alpha$ in prostate cancer cells activates $\mathrm{Ca} 2+-$ primed cascade signaling pathways, which promote matrix metalloproteinase- 9 production and cancer cell invasion. Thus, the inhibition of related molecules in the FAP $\alpha$ signaling pathway or related signaling pathways of the interaction between FAP $\alpha+$ myofibroblasts and tumor cells may become a new strategy to inhibit tumor progression. This study showed that Talabostat inhibited pancreatic cancer cell migration, invasion, and metastasis by FAP $\alpha+$ PSCs in vitro and in vivo, respectively. The treatment strategy for pancreatic cancer stroma may improve the comprehensive therapeutic effect of pancreatic cancer.

TGF $\beta$ is involved in tumor cell proliferation, apoptosis, angiogenesis, immunosuppression, invasion, and metastasis (29). TGF $\beta$ in pancreatic tissue is involved in the regulation of tumor-associated PSCs (30) and promotes the progression of pancreatic cancer. Shukla et al. (31) found that tumor cells can promote the transformation of fibroblasts into myofibroblasts in tumor stroma and further promote tumor cell migration, invasion, and the epithelialmesenchymal transition through TGF $\beta 1$. The results of the present study showed that pancreatic cancer cells can induce FAP $\alpha$ expression by TGF $\beta 1$. When TGF $\beta 1$-neutralizing antibody was added, the effect of inducing FAP $\alpha$ expression can be reduced. Thus, pancreatic cancer cells are involved in FAP $\alpha$ expression in PSCs through TGF $\beta 1$, which, in turn, affects the tumor microenvironment of pancreatic cancer.

CXC, which is a family of chemokines, plays an important role in cancer progression (32). CXCR2, which was originally found in neutrophils (33), eosinophils (34), monocytes (35), and macrophages (36), is involved in the regulation of the motion of these cells. CXCR2 is activated by the chemokines CXCL1-3 and CXCL5-8. The results of the present study showed that CXCL1 and its receptor CXCR2 were highly expressed in many cancers and important factors influencing prognosis. In high-grade ovarian cancer, CXCR2 is an independent risk factor for a poor prognosis. Patients with high CXCR2 expression have a short survival time and are likely to relapse after surgery (37). CXCL1 and its receptor CXCR2 are highly 

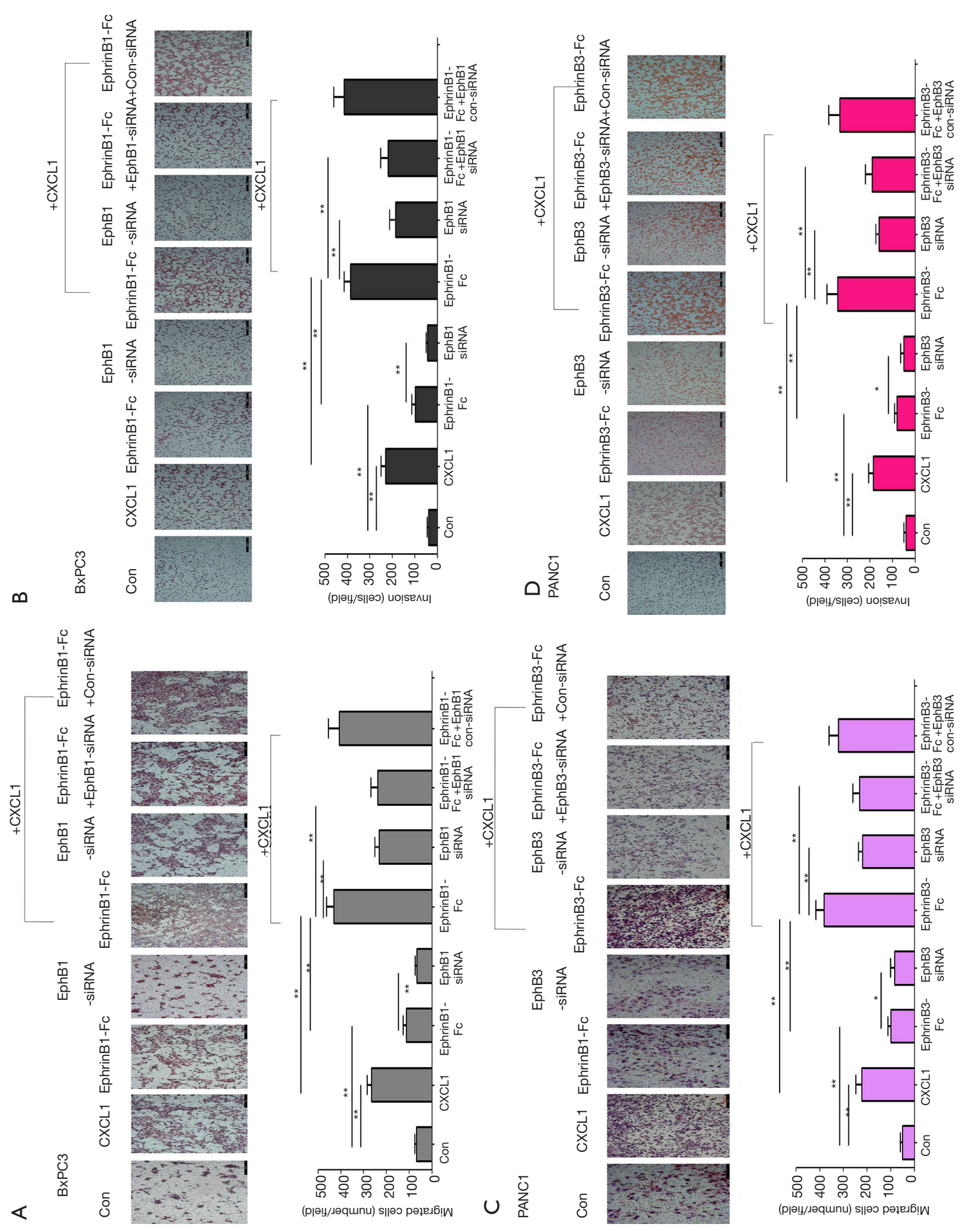

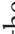

F

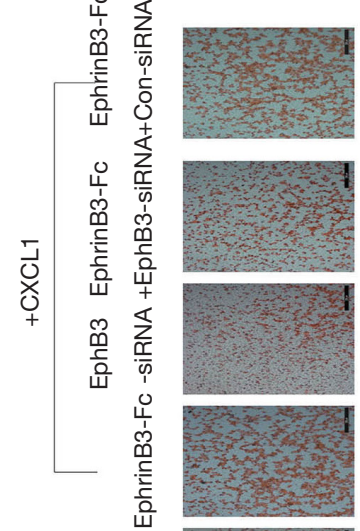

离 $\frac{\mathbb{c}}{\mathrm{c}}$
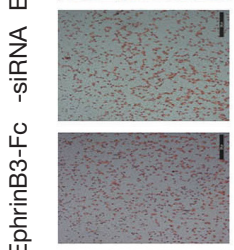

ปَّ

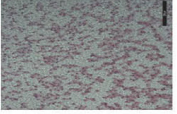

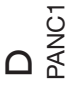

¿ั

官

(p|ə!!/s||əว) uo!̣senu|

$\pm 2$

(2)

$\frac{0}{2} 0^{\circ}$

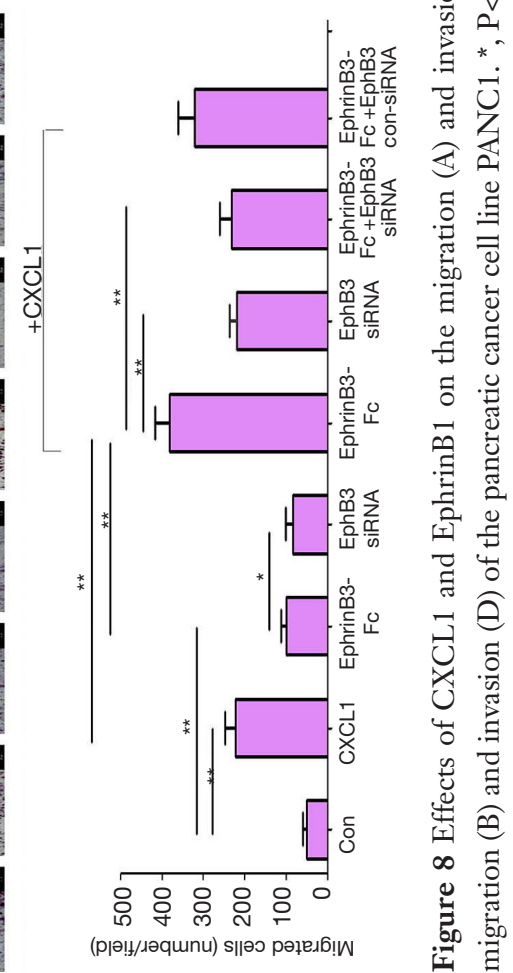


expressed in the tissue samples of different stages of colorectal cancer (38). In colon cancer, increased CXCL1 expression is associated with tumor size, stage, depth of invasion, lymph node metastasis, and patient survival. CXCL1 promotes the invasion of colon cancer cells (39). CXCR1 and CXCR2 are also highly expressed in pancreatic cancer cell lines and pancreatic cancer tissues (40). Using a cytokine chip to compare differential cytokines expressed by FAP $\alpha+$ and FAP $\alpha-$ PSCs, FAP $\alpha+$ PSCs were shown to highly express CXCL1, and CXCL1 promotes pancreatic cell migration and invasion.

As the largest family of tyrosine kinases, the Eph receptor has 14 members, and the binding site of its ligand, Ephrin, is located in the cell membrane, which is directly contacted by cells, triggering subsequent biological processes. Eph and Ephrin are expressed differently in different tumors and can play different roles in promoting tumor progression or inhibiting tumor development. In breast cancer, EphA2 and EphB4 expression levels are higher than those in normal mammary epithelial cells, and high expression of EphA2 is associated with a poor prognosis $(41,42)$. EphB expression at the initial stage of colon cancer accelerates the onset of oncogenic mutations and regulates the involvement of peripheral mesenchyme in colon cancer progression. As colon cancer progresses, the EphB expression levels decrease, thereby accelerating colon cancer cell migration, invasion, and metastasis $(43,44)$. Duxbury et al. $(45)$ found that high EphA2 expression promotes MMP2 expression dependent on the FAK pathway and promotes pancreatic cancer cell invasion. Iiizumi et al. (46) found that high EphA4 expression promoted the growth of pancreatic cancer cells and inhibited the growth of pancreatic cancer cells by regulating the EphB4 and EphrinA3 ligand signaling pathways. However, the role of EphB in the progression of pancreatic cancer is lacking. The results of the present study showed that, under the influence of FAP $\alpha+$ PSCs, the expression levels of the phosphorylated EphB1 and EphB3 proteins are increased in pancreatic cancer cells. EphB1 and EphB3 promote pancreatic cancer cell migration and invasion by binding their ligands Ephrin B1 and EphrinB3, respectively. CXCR2 interacts with EphB1, CXCR2 and EphB3, and CXCL1, EphrinB1 and EphrinB3 can synergistically promote pancreatic cancer cell migration and invasion.

The serine/threonine protein kinase (Akt) is a downstream target of phosphatidylinositol-3 kinase (PI3K). Activated Akt is involved in numerous biological processes, such as cell growth, apoptosis, cell cycle, differentiation,

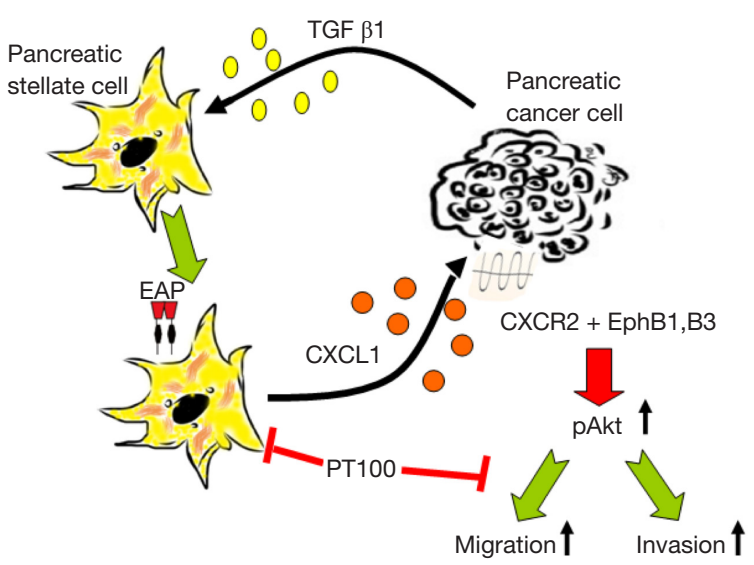

Figure 9 Scheme of this study.

transcription, translation, and glucose metabolism. An increasing number of studies has shown that Akt is involved in the regulation of tumor cell proliferation, apoptosis, tumor cell migration and adhesion, angiogenesis, and extracellular matrix degradation (47). In breast and ovarian cancer, Akt2 overexpression can regulate the expression of $\beta 1$ in type IV collagen, thereby promoting tumor cell invasion and metastasis (48). High Akt expression can induce the epithelial-mesenchymal transition and enhance the ability of squamous cell carcinoma to invade and metastasize (49). Akt signaling promotes tumor necrosis factor-induced endothelial cell migration and regulates tumor angiogenesis (50). During tumor invasion and metastasis, platelet growth factor promotes MMP3 production via the PI3K/Akt pathway, which, in turn, affects tumor angiogenesis (51). The results of this study indicated that CXCL1 and EphrinB1 and EphrinB3 can affect the Akt signaling pathway, promote Akt phosphorylation, and synergistically promote pancreatic cancer cell migration and invasion.

Taken together, pancreatic cancer cells can induce FAP $\alpha+$ PSCs by TGF- $\beta 1$. Clinically, a higher number of $\mathrm{FAP} \alpha+$ PSCs predicts a poorer survival of patients. FAP $\alpha+$ PSCs can produce CXCL1, which binds to CXCR2 and activates EphrinB1 and EphrinB3, finally leading to Akt phosphorylation to promote the invasion and migration of cancer cells. FAP $\alpha$ inhibition significantly weakens the effects of FAP $\alpha+$ PSCs. This study unveils the mechanistic roles of the interactions between FAP $\alpha+$ PSCs and pancreatic cancer cells, presenting new targets for the comprehensive treatments of pancreatic cancer (Figure 9). As well known, TGF- $\beta 1$ is a multifunctional factor which 
could potentially affect other roles of PSCs, besides induction of FAP $\alpha$. To directly confirm the roles of FAP $\alpha$ in PSCs, knock-in of FAPais more reliable, however it is technically challenging, which we are keeping trying.

\section{Acknowledgments}

Funding: This work was supported by National Natural Science Foundation of China $(81673023,81872501$, 81560387 and 81272573). "Medical Excellence Award" funded by the creative research development grant from the first affiliated hospital of Guangxi Medical University (180327). Beijing Natural Science Foundation of China (7172177) and CAMS innovation Fun for Medical Sciences (CIFMS), NWA0564-3.

\section{Footnote}

Conflicts of Interest: The authors have no conflicts of interest to declare.

Ethical Statement: The authors are accountable for all aspects of the work in ensuring that questions related to the accuracy or integrity of any part of the work are appropriately investigated and resolved. All of the patients signed the informed consent for scientific use of biosamples. This study was approved by the ethic committees of Peking Union Medical College Hospital and the First Affiliated Hospital of Guangxi Medical University (No. JS987).

\section{References}

1. Wu WM, Jin G, Wang CY, et al. The current surgical treatment of pancreatic cancer in China: a national wide cross-sectional study. J Pancreatol 2019;2:16-21.

2. Mahadevan D, Von Hoff DD. Tumor-stroma interactions in pancreatic ductal adenocarcinoma. Mol Cancer Ther 2007;6:1186-97.

3. Erkan M, Reiser-Erkan C, Michalski CW, et al. The Impact of the Activated Stroma on Pancreatic Ductal Adenocarcinoma Biology and Therapy Resistance. Curr Mol Med 2012;12:288-303.

4. Grippo PJ, Fitchev PS, Bentrem DJ, et al. Concurrent PEDF deficiency and Kras mutation induce invasive pancreatic cancer and adipose-rich stroma in mice. Gut 2012;61:1454-64.

5. Grisendi G, Bussolari R, Veronesi E, et al. Understanding tumor-stroma interplays for targeted therapies by armed mesenchymal stromal progenitors: the Mesenkillers. Am J Cancer Res 2011;1:787-805.

6. Apte MV, Haber PS, Applegate TL, et al. Periacinar stellate shaped cells in rat pancreas: identification, isolation, and culture. Gut 1998;43:128-33.

7. Bachem MG, Schneider E, Gross H, et al. Identification, culture, and characterization of pancreatic stellate cells in rats and humans. Gastroenterology 1998;115:421-32.

8. Vonlaufen A, Joshi S, Qu C, et al. Pancreatic stellate cells: partners in crime with pancreatic cancer cells. Cancer Res 2008;68:2085-93.

9. Hwang RF, Moore T, Arumugam T, et al. Cancerassociated stromal fibroblasts promote pancreatic tumor progression. Cancer Res 2008;68:918-26.

10. Kennedy A, Dong H, Chen D, et al. Elevation of seprase expression and promotion of an invasive phenotype by collagenous matrices in ovarian tumor cells. Int $\mathrm{J}$ Cancer 2009;124:27-35.

11. Ariga N, Sato E, Ohuchi N, et al. Stromal expression of fibroblast activation protein/seprase, a cell membrane serine proteinase and gelatinase, is associated with longer survival in patients with invasive ductal carcinoma of breast. Int J Cancer 2001;95:67-72.

12. Kloft C, Graefe EU, Tanswell P, et al. Population pharmacokinetics of sibrotuzumab, a novel therapeutic monoclonal antibody, in cancer patients. Invest New Drugs 2004;22:39-52.

13. Loeffler M, Kruger JA, Niethammer AG, et al. Targeting tumor-associated fibroblasts improves cancer chemotherapy by increasing intratumoral drug uptake. J Clin Invest 2006;116:1955-62.

14. Han HK, Amidon GL. Targeted prodrug design to optimize drug delivery. AAPS PharmSci 2000;2:E6.

15. Gonzalez-Gronow M, Grenett HE, Gawdi G, et al. Angiostatin directly inhibits human prostate tumor cell invasion by blocking plasminogen binding to its cellular receptor, CD26. Exp Cell Res 2005;303:22-31.

16. Henry LR, Lee HO, Lee JS, et al. Clinical implications of fibroblast activation protein in patients with colon cancer. Clin Cancer Res 2007;13:1736-41.

17. Mathison A, Liebl A, Bharucha J, et al. Pancreatic stellate cell models for transcriptional studies of desmoplasiaassociated genes. Pancreatology 2010;10:505-16.

18. Adams S, Miller GT, Jesson MI, et al. PT-100, a small molecule dipeptidyl peptidase inhibitor, has potent antitumor effects and augments antibody-mediated cytotoxicity via a novel immune mechanism. Cancer Res 
2004;64:5471-80.

19. Apte MV, Park S, Phillips PA, et al. Desmoplastic reaction in pancreatic cancer: role of pancreatic stellate cells. Pancreas 2004;29:179-87.

20. Acharya PS, Zukas A, Chandan V, et al. Fibroblast activation protein: a serine protease expressed at the remodeling interface in idiopathic pulmonary fibrosis. Hum Pathol 2006;37:352-60.

21. Monsky WL, Lin CY, Aoyama A, et al. A potential marker protease of invasiveness, seprase, is localized on invadopodia of human malignant melanoma cells. Cancer Res 1994;54:5702-10.

22. Ajami K, Abbott CA, Obradovic M, et al. Structural requirements for catalysis, expression, and dimerization in the CD26/DPIV gene family. Biochemistry 2003;42:694-701.

23. Garin-Chesa P, Old LJ, Rettig WJ. Cell surface glycoprotein of reactive stromal fibroblasts as a potential antibody target in human epithelial cancers. Proc Natl Acad Sci U S A 1990;87:7235-9.

24. Scanlan MJ, Raj BK, Calvo B, et al. Molecular cloning of fibroblast activation protein alpha, a member of the serine protease family selectively expressed in stromal fibroblasts of epithelial cancers. Proc Natl Acad Sci U S A 1994;91:5657-61.

25. Goscinski MA, Suo Z, Florenes VA, et al. FAP-alpha and uPA show different expression patterns in premalignant and malignant esophageal lesions. Ultrastruct Pathol 2008;32:89-96.

26. Kraman M, Bambrough PJ, Arnold JN, et al. Suppression of antitumor immunity by stromal cells expressing fibroblast activation protein-alpha. Science 2010;330:827-30.

27. Cheng JD, Dunbrack RL Jr, Valianou M, et al. Promotion of tumor growth by murine fibroblast activation protein, a serine protease, in an animal model. Cancer Res 2002;62:4767-72.

28. Gonzalez-Gronow M, Grenett HE, Weber MR, et al. Interaction of plasminogen with dipeptidyl peptidase IV initiates a signal transduction mechanism which regulates expression of matrix metalloproteinase- 9 by prostate cancer cells. Biochem J 2001;355:397-407.

29. Achyut BR, Yang L. Transforming growth factor-beta in the gastrointestinal and hepatic tumor microenvironment. Gastroenterology 2011;141:1167-78.

30. Erkan M, Adler G, Apte MV, et al. StellaTUM: current consensus and discussion on pancreatic stellate cell research. Gut 2012;61:172-8.

31. Shukla A, Edwards R, Yang Y, et al. CLIC4 regulates
TGF-beta-dependent myofibroblast differentiation to produce a cancer stroma. Oncogene 2014;33:842-50.

32. Vinader $\mathrm{V}$, Afarinkia $\mathrm{K}$. The emerging role of $\mathrm{CXC}$ chemokines and their receptors in cancer. Future Med Chem 2012;4:853-67.

33. Del Rio L, Bennouna S, Salinas J, et al. CXCR2 deficiency confers impaired neutrophil recruitment and increased susceptibility during Toxoplasma gondii infection. J Immunol 2001;167:6503-9.

34. Petering H, Gotze O, Kimmig D, et al. The biologic role of interleukin-8: functional analysis and expression of CXCR1 and CXCR2 on human eosinophils. Blood 1999;93:694-702.

35. Weber C, Kraemer S, Drechsler M, et al. Structural determinants of MIF functions in CXCR2-mediated inflammatory and atherogenic leukocyte recruitment. Proc Natl Acad Sci U S A 2008;105:16278-83.

36. Boisvert WA, Rose DM, Johnson KA, et al. Up-regulated expression of the CXCR2 ligand KC/GRO-alpha in atherosclerotic lesions plays a central role in macrophage accumulation and lesion progression. Am J Pathol 2006;168:1385-95.

37. Yang G, Rosen DG, Liu G, et al. CXCR2 promotes ovarian cancer growth through dysregulated cell cycle, diminished apoptosis, and enhanced angiogenesis. Clin Cancer Res 2010;16:3875-86.

38. Rubie C, Kollmar O, Frick VO, et al. Differential CXC receptor expression in colorectal carcinomas. Scand J Immunol 2008;68:635-44.

39. Wen Y, Giardina SF, Hamming D, et al. GROalpha is highly expressed in adenocarcinoma of the colon and downregulates fibulin-1. Clin Cancer Res 2006;12:5951-9.

40. Kuwada Y, Sasaki T, Morinaka K, et al. Potential involvement of IL-8 and its receptors in the invasiveness of pancreatic cancer cells. Int J Oncol 2003;22:765-71.

41. Martin KJ, Patrick DR, Bissell MJ, et al. Prognostic breast cancer signature identified from 3D culture model accurately predicts clinical outcome across independent datasets. PLoS One 2008;3:e2994.

42. Fournier MV, Martin KJ, Kenny PA, et al. Gene expression signature in organized and growth-arrested mammary acini predicts good outcome in breast cance. Cancer Res 2006;66:7095-102.

43. Davalos V, Dopeso H, Castano J, et al. EPHB4 and survival of colorectal cancer patients. Cancer Res 2006;66:8943-8.

44. Oshima H, Oshima M, Kobayashi M, et al. Morphological and molecular processes of polyp formation in 
Apc(delta716) knockout mice. Cancer Res 1997;57:1644-9.

45. Duxbury MS, Ito H, Zinner MJ, et al. Ligation of EphA2 by Ephrin A1-Fc inhibits pancreatic adenocarcinoma cellular invasiveness. Biochem Biophys Res Commun 2004;320:1096-102.

46. Iiizumi M, Hosokawa M, Takehara A, et al. EphA4 receptor, overexpressed in pancreatic ductal adenocarcinoma, promotes cancer cell growth. Cancer Sci 2006;97:1211-6

47. Hennessy BT, Smith DL, Ram PT, et al. Exploiting the PI3K/AKT pathway for cancer drug discovery. Nat Rev Drug Discov 2005;4:988-1004.

48. Arboleda MJ, Lyons JF, Kabbinavar FF, et al.

Overexpression of AKT2/protein kinase Bbeta leads

to up-regulation of beta1 integrins, increased invasion,

Cite this article as: Wen $\mathrm{Z}$, Liu Q, Wu J, Xu B, Wang J, Liang L, Guo Y, Peng M, Zhao Y, Liao Q. Fibroblast activation protein $\alpha$-positive pancreatic stellate cells promote the migration and invasion of pancreatic cancer by CXCL1mediated Akt phosphorylation. Ann Transl Med 2019;7(20):532. doi: 10.21037/atm.2019.09.164 and metastasis of human breast and ovarian cancer cells. Cancer Res 2003;63:196-206.

49. Grille SJ, Bellacosa A, Upson J, et al. The protein kinase Akt induces epithelial mesenchymal transition and promotes enhanced motility and invasiveness of squamous cell carcinoma lines. Cancer Res 2003;63:2172-8.

50. Zhang R, Xu Y, Ekman N, et al. Etk/Bmx transactivates vascular endothelial growth factor 2 and recruits phosphatidylinositol 3-kinase to mediate the tumor necrosis factor-induced angiogenic pathway. J Biol Chem 2003;278:51267-76.

51. Kanaki T, Bujo H, Mori S, et al. Functional analysis of aortic endothelial cells expressing mutant PDGF receptors with respect to expression of matrix metalloproteinase-3. Biochem Biophys Res Commun 2002;294:231-7. 